\title{
Trends in cancer mortality in the Americas, 1970-2000
}

\author{
C. Bosetti ${ }^{1}$, M. Malvezzi ${ }^{1}$, L. Chatenoud ${ }^{1}$, E. Negri ${ }^{1}$, F. Levi ${ }^{2} \&$ C. La Vecchia ${ }^{1,3}$ \\ ${ }^{1}$ Istituto di Ricerche Farmacologiche 'Mario Negri', Via Eritrea 62, 20157 Milan; ${ }^{2}$ Unité d'Epidémiologie du Cancer and Registres Vaudois et Neuchâtelois des \\ Tumeurs, Institut universitaire de médecine sociale et préventive, Centre Hospitalier Universitaire Vaudois, Falaises 1, 1011 Lausanne, Switzerland; ${ }^{3}$ Istituto di \\ Statistica Medica e Biometria, Università degli Studi di Milano, Via Venezian 1, 20133 Milan, Italy \\ Received 7 September 2004; revised 20 October 2004; accepted 25 October 2004
}

\begin{abstract}
Background: Data and statistics on cancer mortality over the last decades are available for most developed countries, while they are more difficult to obtain, in a standardized and comparable format, for countries of Latin America.

Patients and methods: Age standardized (world population) mortality rates around the year 2000, derived from the WHO database, are presented for 14 selected cancers and total cancer in 10 countries of Latin America, plus, for comparative purposes, Canada and the USA. Trends in mortality are also given over the period 1970-2000.

Results: In 2000, the highest total cancer mortality for males was observed in Argentina and Chile, with rates comparable to those of Canada and the USA, i.e. about 155/100000. For women, Chile and Cuba had the highest rates in Latin America (114 and 103/100 000, respectively), again comparable to those of North America (around 105/100 000). These reflect the comparatively high mortality from cancer of the stomach (for Chile), lung and intestines (for Argentina) in men, and of stomach and uterus (for Chile), intestines and lung (for Cuba) in women. Colombia, Ecuador and Mexico had the lowest total cancer mortality for men, due to low mortality from stomach, colorectal and lung cancer. For women, the lowest rates were in Brazil and Puerto Rico, reflecting their low stomach and cervical cancer rates. In Argentina, Chile, Colombia, Costa Rica and Venezuela cancer mortality rates tended to decline, particularly in men. Rates were stable in Ecuador and Puerto Rico, and were increasing in Mexico and Cuba.

Conclusions: Mortality from some common cancers (including colorectal and lung) is still low in Latin America compared with Canada and the USA, and decreasing trends have been observed in the last decades for some cancer sites (including stomach, uterus, lung and other tobacco-related cancers) in several countries. However, mortality from female lung and breast cancers has been increasing in most countries of Latin America, and several countries still show an extremely elevated mortality from cancer of the cervix. Selected neoplasms amenable to treatment, including testis and leukemias, also show unsatisfactory trends in Latin America.
\end{abstract}

Key words: cancer, Latin America, mortality, trends

\section{Introduction}

Data and statistics on cancer mortality over the last few decades are easily available for most developed countries, including Europe [1], North America and Japan [2-5], while they are more difficult to obtain, in a standardized and comparable format, for countries of Latin America [3, 6].

In the early 1990s, a summary overview was published of cancer mortality in the Americas between 1955 and 1989 [6]. In the present report, trends in cancer mortality in selected

*Correspondence to: Dr C. Bosetti, Laboratorio di Epidemiologia, Istituto di Ricerche Farmacologiche 'Mario Negri', Via Eritrea 62, 20157 Milan, Italy. Tel: +39-02-39014526; Fax: +39-02-33200231;

E-mail: bosetti@marionegri.it countries of the Americas (including, mainly for comparative purposes, the USA and Canada) have been updated to the year 2000. Since long-term trends provide useful information to understand recent patterns and to project most likely future trends [7], this paper also gives a summary overview of trends since 1970. The major aim of the present work is to provide a comprehensive documentation of the patterns of cancer mortality trends in the Americas, and has therefore relevant implications for further investigation and public health intervention.

\section{Patients and methods}

Certified deaths from 14 selected cancer sites and for total cancer mortality for the calendar period considered (1970-2000), stratified for sex and 5-year age groups, were derived from the WHO database [8] for 
Table 1. Calendar years and countries for which data were missing

\begin{tabular}{|c|c|c|c|c|c|}
\hline \multirow[t]{2}{*}{ Country } & \multicolumn{5}{|l|}{ Cancer sites (ICD IX) } \\
\hline & Mouth and pharynx (140-149) & Esophagus (150) & Stomach (151) & Intestines $(152-154,159.0)$ & Larynx (161) \\
\hline Argentina & 1971-1976, 1998, 1999 & 1971-1976, 1998, 1999 & 1971-1976, 1998, 1999 & 1971-1976, 1998, 1999 & $1971-1976,1998,1999$ \\
\hline Brazil $^{\mathrm{a}}$ & $1970-1985,1996-1999$ & $1970-1985,1996-1999$ & $1970-1985,1996-1999$ & $1970-1985,1996-1999$ & $1970-1985,1996-1999$ \\
\hline Chile & - & - & - & - & - \\
\hline Colombia & $\begin{array}{l}\text { 1970, 1971, 1973, 1978-1983, } \\
1987-1990,1999\end{array}$ & $\begin{array}{l}\text { 1970, 1971, 1973, 1978-1983, } \\
1987-1990,1999\end{array}$ & $\begin{array}{l}\text { 1970, 1971, 1973, 1978-1983, } \\
1987-1990,1999\end{array}$ & $\begin{array}{l}\text { 1970, 1971, 1973, 1978-1983, } \\
1987-1990,1999\end{array}$ & $\begin{array}{l}\text { 1970, 1971, 1973, 1978-1983, } \\
1987-1990,1999\end{array}$ \\
\hline Costa Rica & - & - & - & - & - \\
\hline Cuba & - & - & - & - & - \\
\hline Ecuador & $1976,1981,1983,1989$ & 1976, 1981, 1983, 1989 & 1976, 1981, 1983, 1989 & $1976,1981,1983,1989$ & $1976,1981,1983,1989$ \\
\hline Mexico & 1977, 1984 & 1977, 1984 & 1977, 1984 & 1977, 1984 & 1977, 1984 \\
\hline Puerto Rico & 1978 & 1978 & 1978 & 1978 & 1978 \\
\hline Venezuela & 1984, 1991, 1995 & 1984, 1991, 1995 & 1984, 1991, 1995 & 1984, 1991, 1995 & 1984, 1991, 1995 \\
\hline Canada & 1999 & 1999 & 1999 & 1999 & 1999 \\
\hline \multirow[t]{2}{*}{ USA } & - & - & - & - & - \\
\hline & Lung (162) & Bone (170) & Breast (174) & Uterus $(179-182)$ & Ovary (183) \\
\hline Argentina & 1971-1976, 1998, 1999 & 1971-1976, 1998, 1999 & 1971-1976, 1998, 1999 & 1971-1976, 1998, 1999 & 1970-1979, 1982-1996, 1998, 1999 \\
\hline Brazil $^{\mathrm{a}}$ & $1970-1985,1996-1999$ & $1970-1985,1996-1999$ & $1970-1985,1996-1999$ & $1970-1985,1996-1999$ & $1970-1999$ \\
\hline Chile & - & - & - & - & $1970-1982,1984-1996$ \\
\hline Colombia & $\begin{array}{l}1970,1971,1973,1978-1983 \\
1987-1990,1999\end{array}$ & $\begin{array}{l}\text { 1970, 1971, 1973, 1978-1983, } \\
1987-1990,1999\end{array}$ & $\begin{array}{l}\text { 1970, 1971, 1973, 1978-1983, } \\
1987-1990,1999\end{array}$ & $\begin{array}{l}\text { 1970, 1971, 1973, 1978-1983, } \\
1987-1990,1999\end{array}$ & 1970-1996, 1999 \\
\hline Costa Rica & - & - & - & - & $1970-1996$ \\
\hline Cuba & - & - & - & - & $1970-1999$ \\
\hline Ecuador & $1976,1981,1983,1989$ & 1976, 1981, 1983, 1989 & 1976, 1981, 1983, 1989 & 1976, 1981, 1983, 1989 & $1970-1996$ \\
\hline Mexico & 1977, 1984 & 1977,1984 & 1977, 1984 & 1977, 1984 & 1970, 1975-1997 \\
\hline Puerto Rico & 1978 & 1978 & 1978 & 1978 & $1970-1998$ \\
\hline Venezuela & 1984, 1991, 1995 & 1984, 1991, 1995 & 1984, 1991, 1995 & 1984, 1991, 1995 & $1975,1979,1981-1995$ \\
\hline Canada & 1999 & 1999 & 1999 & 1999 & 1999 \\
\hline \multirow[t]{2}{*}{ USA } & - & - & - & - & 1978 \\
\hline & Prostate (185) & Testis (186) & Bladder (188) & Leukemias (204-208) & All neoplasms (140-239) \\
\hline Argentina & $1971-1976,1998,1999$ & 1970-1979, 1982-1996, 1998, 1999 & 1970-1978, 1998, 1999 & 1971-1976, 1998, 1999 & 1971-1976, 1998, 1999 \\
\hline $\mathrm{Brazil}^{\mathrm{a}}$ & $1970-1985,1996-1999$ & $1970-1999$ & $1970-1985,1996-1999$ & $1970-1985,1996-1999$ & $1970-1985,1996-1999$ \\
\hline Chile & - & $1970-1982,1984-1996$ & $1970-1979$ & - & - \\
\hline Colombia & $\begin{array}{l}1970,1971,1973,1978-1983 \\
1987-1990,1999\end{array}$ & 1970-1996, 1999 & 1970-1983, 1987-1990, 1999 & $\begin{array}{l}1970,1971,1973,1978-1983, \\
1987-1990,1999\end{array}$ & $\begin{array}{l}\text { 1970, 1971, 1973, 1978-1983, } \\
1987-1990,1999\end{array}$ \\
\hline Costa Rica & - & $1970-1996$ & $1970-1979$ & - & - \\
\hline
\end{tabular}




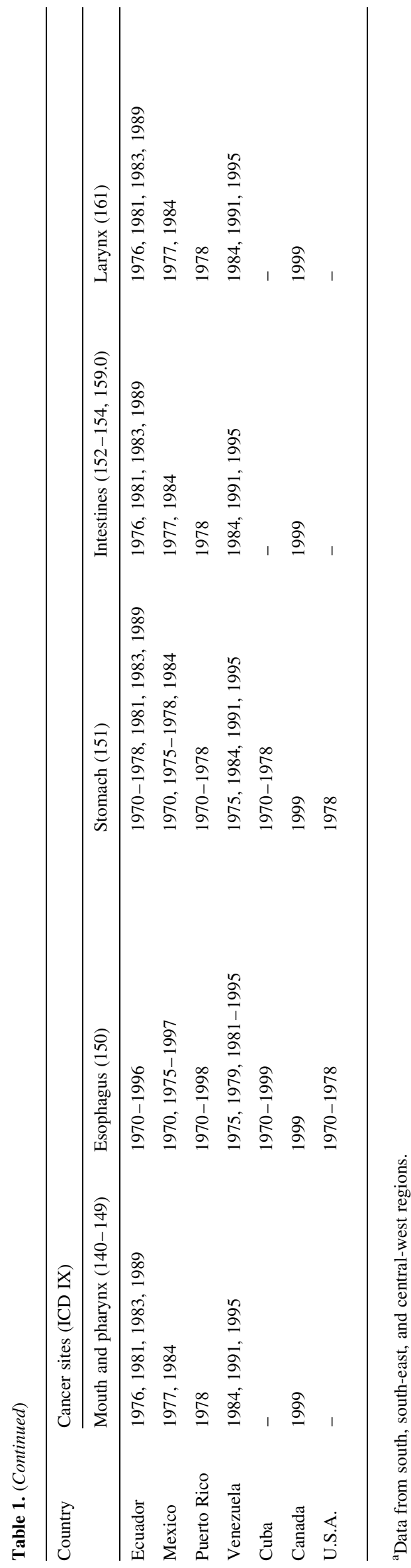

10 countries of Latin America with available and updated mortality and population data, i.e. Argentina, Brazil, Chile, Colombia, Costa Rica, Cuba, Ecuador, Mexico, Puerto Rico and Venezuela, plus Canada and the USA. For Brazil, data from only the south, south-east and central-west regions were available (about 100 million inhabitants).

During the calendar periods considered, three different Revisions of the International Classification of Diseases (ICD) were used [9-11]. Classification of cancer deaths was thus recoded for all calendar periods according to the IX Revision of the ICD [10]. To improve data comparability between different countries and calendar periods, we pooled together all intestinal cancers (chiefly colon and rectum), all uterine cancers (cervix and corpus) and all leukemias. We did not consider some rare cancers (i.e. gallbladder, sarcomas, lymphomas and thyroid), and a few other sites (i.e. liver, pancreas, skin, kidney and brain) which involve major difficulties or inconsistencies in diagnosis and certification.

Estimates of the resident populations, based on official censuses, were obtained from the same WHO database [8] whenever available, and from the Pan American Health Organization (PAHO) [12], when the WHO data were unavailable. Since the PAHO database provided only data for broad age groups, subsequent quinquennia of age were estimated by interpolating from the WHO distribution of the last year available for each country.

From the matrices of certified deaths and resident population, agespecific rates for each 5-year age group and calendar period were computed, for men and women. Age-standardized rates per 100000 population, at all ages and truncated at age 35-64 years, were computed by the direct method, on the basis of the world standard population [13].

In a few countries, data were missing for one or more calendar years (Table 1). No extrapolation was made for missing data.

\section{Results and discussion}

This is essentially a descriptive report, and no inference is made on the statistical significance of rates and trends. A few general comments are, however, included to assist in critical reading and interpretation of results. First, it is important to consider problems related to random variation, which are greater in smaller populations and for rarer cancers. Secondly, and more complex, there are problems of death certification reliability and validity, which may differ in various countries [14-16]. In general, for several common cancer sites, including lung, stomach, colorectum and breast, death certification is sufficiently reliable to permit meaningful inference on trends in most American countries, particularly within countries and under age 65 years. Greater caution is required for a few countries and cancer sites, whose diagnosis and certification can be appreciably influenced by the availability and utilization of diagnostic techniques and the accuracy of death certification, including, among others, bone, prostate and leukemias.

Table 2 includes, for the 14 selected cancers and for each country and sex, the observed number of deaths and the agestandardized (world standard) overall and truncated (35-64 years) mortality rates per 100000 over the most recent year (2000, whenever available). Figure 1 gives the histograms of the overall age-standardized death rates for total cancer mortality for each cancer site (by country and sex) for the year 2000 (or the most recent calendar year available). Figure 2 shows the trends in the world standardized rates (at all ages and truncated at 35-64 years) for each cancer site in the 12 
Table 2. Certified number of deaths and age-standardized (world standard) overall and truncated 35-64 years mortality rates per 100000 for 14 cancer sites plus all cancers, in selected countries of the Americas in 2000 (unless mentioned in parentheses)

\begin{tabular}{|c|c|c|c|c|c|c|}
\hline \multirow[t]{2}{*}{ Country } & \multicolumn{3}{|l|}{ Men } & \multicolumn{3}{|l|}{ Women } \\
\hline & $\begin{array}{l}\text { Deaths } \\
\text { no. }\end{array}$ & $\begin{array}{l}\text { World } \\
\text { standard }\end{array}$ & $\begin{array}{l}\text { Truncated } \\
35-64\end{array}$ & $\begin{array}{l}\text { Deaths } \\
\text { no. }\end{array}$ & $\begin{array}{l}\text { World } \\
\text { standard }\end{array}$ & $\begin{array}{l}\text { Truncated } \\
35-64\end{array}$ \\
\hline \multicolumn{7}{|c|}{ Mouth and pharynx } \\
\hline Argentina & 617 & 3.34 & 6.66 & 200 & 0.74 & 1.02 \\
\hline Brazil (1995) & 2576 & 6.64 & 13.15 & 536 & 1.15 & 1.77 \\
\hline Chile (1999) & 125 & 2.16 & 3.30 & 47 & 0.55 & 0.57 \\
\hline $\begin{array}{c}\text { Colombia } \\
\text { (1999) }\end{array}$ & 250 & 2.00 & 2.41 & 181 & 1.22 & 1.41 \\
\hline Costa Rica & 37 & 2.66 & 3.51 & 17 & 1.13 & 1.25 \\
\hline Cuba & 377 & 5.74 & 9.87 & 115 & 1.48 & 1.94 \\
\hline Ecuador & 54 & 1.35 & 1.57 & 22 & 0.48 & 0.48 \\
\hline Mexico & 498 & 1.70 & 2.19 & 275 & 0.77 & 0.86 \\
\hline Puerto Rico & 111 & 5.22 & 9.98 & 25 & 0.86 & 1.09 \\
\hline Venezuela & 173 & 2.47 & 3.78 & 86 & 1.07 & 1.19 \\
\hline Canada & 594 & 2.77 & 4.46 & 307 & 1.04 & 1.36 \\
\hline USA & 4952 & 2.73 & 4.81 & 2540 & 0.98 & 1.36 \\
\hline \multicolumn{7}{|l|}{ Esophagus } \\
\hline Argentina & 1398 & 7.16 & 9.50 & 582 & 2.05 & 2.14 \\
\hline Brazil (1995) & 3024 & 7.99 & 14.23 & 966 & 2.09 & 3.10 \\
\hline Chile (1999) & 446 & 7.54 & 5.30 & 305 & 3.53 & 2.75 \\
\hline $\begin{array}{c}\text { Colombia } \\
\text { (1999) }\end{array}$ & 411 & 3.40 & 3.19 & 228 & 1.50 & 1.41 \\
\hline Costa Rica & 29 & 2.27 & 2.63 & 17 & 1.04 & 0.23 \\
\hline Cuba & 293 & 4.52 & 7.31 & 100 & 1.40 & 2.10 \\
\hline Ecuador & 74 & 2.00 & 1.39 & 25 & 0.57 & 0.74 \\
\hline Mexico & 551 & 1.89 & 2.23 & 219 & 0.61 & 0.59 \\
\hline Puerto Rico & 117 & 5.09 & 7.26 & 38 & 1.24 & 0.97 \\
\hline Venezuela & 165 & 2.44 & 3.13 & 54 & 0.67 & 0.45 \\
\hline Canada & 1052 & 4.79 & 6.55 & 340 & 1.11 & 1.02 \\
\hline USA & 9279 & 4.98 & 7.60 & 2953 & 1.09 & 1.32 \\
\hline \multicolumn{7}{|l|}{ Stomach } \\
\hline Argentina & 1965 & 9.93 & 12.31 & 1004 & 3.75 & 5.00 \\
\hline Brazil (1995) & 5710 & 15.17 & 20.65 & 2805 & 5.90 & 7.32 \\
\hline Chile (1999) & 2014 & 33.75 & 35.31 & 1024 & 12.11 & 11.86 \\
\hline $\begin{array}{c}\text { Colombia } \\
\text { (1999) }\end{array}$ & 2469 & 19.93 & 24.76 & 1643 & 10.97 & 12.02 \\
\hline Costa Rica & 356 & 27.20 & 28.55 & 212 & 13.68 & 12.32 \\
\hline Cuba & 463 & 6.86 & 9.62 & 261 & 3.52 & 4.68 \\
\hline Ecuador & 781 & 20.66 & 21.67 & 586 & 13.58 & 15.02 \\
\hline Mexico & 2760 & 9.32 & 11.06 & 2249 & 6.36 & 7.89 \\
\hline Puerto Rico & 167 & 6.97 & 9.07 & 110 & 3.42 & 3.01 \\
\hline Venezuela & 1013 & 14.89 & 15.47 & 676 & 8.46 & 8.88 \\
\hline Canada & 1195 & 5.16 & 5.75 & 793 & 2.55 & 3.01 \\
\hline USA & 7328 & 3.65 & 4.65 & 5317 & 1.84 & 2.27 \\
\hline
\end{tabular}

Table 2. (Continued)

\begin{tabular}{|c|c|c|c|c|c|c|}
\hline \multirow[t]{2}{*}{ Country } & \multicolumn{3}{|l|}{ Men } & \multicolumn{3}{|l|}{ Women } \\
\hline & $\begin{array}{l}\text { Deaths } \\
\text { no. }\end{array}$ & $\begin{array}{l}\text { World } \\
\text { standard }\end{array}$ & $\begin{array}{l}\text { Truncated } \\
35-64\end{array}$ & $\begin{array}{l}\text { Deaths } \\
\text { no. }\end{array}$ & $\begin{array}{l}\text { World } \\
\text { standard }\end{array}$ & $\begin{array}{l}\text { Truncated } \\
35-64\end{array}$ \\
\hline \multicolumn{7}{|l|}{ Intestine } \\
\hline Argentina & 2986 & 14.89 & 16.20 & 2609 & 9.31 & 10.97 \\
\hline Brazil (1995) & 2341 & 6.11 & 7.78 & 2718 & 5.67 & 6.86 \\
\hline Chile (1999) & 482 & 7.96 & 7.87 & 632 & 7.36 & 6.87 \\
\hline $\begin{array}{c}\text { Colombia } \\
\text { (1999) }\end{array}$ & 700 & 5.47 & 7.12 & 887 & 5.84 & 6.86 \\
\hline Costa Rica & 90 & 6.96 & 6.83 & 129 & 8.53 & 8.66 \\
\hline Cuba & 736 & 10.46 & 11.87 & 999 & 12.84 & 15.06 \\
\hline Ecuador & 131 & 3.42 & 4.08 & 191 & 4.48 & 4.95 \\
\hline Mexico & 1316 & 4.38 & 5.58 & 1306 & 3.65 & 4.96 \\
\hline Puerto Rico & 275 & 11.91 & 15.89 & 243 & 8.05 & 10.30 \\
\hline Venezuela & 520 & 7.49 & 8.73 & 543 & 6.78 & 8.62 \\
\hline Canada & 3549 & 15.43 & 17.82 & 3094 & 9.75 & 11.39 \\
\hline USA & 28462 & 13.96 & 16.33 & 29015 & 9.82 & 11.48 \\
\hline \multicolumn{7}{|l|}{ Larynx } \\
\hline Argentina & 849 & 4.50 & 7.67 & 93 & 0.37 & 0.65 \\
\hline Brazil (1995) & 1819 & 4.81 & 9.06 & 254 & 0.56 & 0.98 \\
\hline Chile (1999) & 101 & 1.73 & 1.80 & 24 & 0.29 & 0.28 \\
\hline $\begin{array}{c}\text { Colombia } \\
\text { (1999) }\end{array}$ & 330 & 2.72 & 3.10 & 101 & 0.70 & 0.77 \\
\hline Costa Rica & 22 & 1.69 & 1.08 & 2 & 0.13 & 0.23 \\
\hline Cuba & 472 & 7.26 & 11.69 & 89 & 1.23 & 1.79 \\
\hline Ecuador & 36 & 0.90 & 0.88 & 12 & 0.27 & 0.13 \\
\hline Mexico & 695 & 2.44 & 2.79 & 153 & 0.44 & 0.49 \\
\hline Puerto Rico & 70 & 3.21 & 5.60 & 10 & 0.32 & 0.32 \\
\hline Venezuela & 240 & 3.54 & 5.28 & 41 & 0.54 & 0.49 \\
\hline Canada & 416 & 1.87 & 2.34 & 90 & 0.33 & 0.28 \\
\hline USA & 3041 & 1.62 & 2.39 & 820 & 0.35 & 0.49 \\
\hline \multicolumn{7}{|l|}{ Lung } \\
\hline Argentina & 6691 & 35.02 & 54.70 & 1718 & 6.88 & 11.41 \\
\hline Brazil (1995) & 7689 & 20.73 & 28.67 & 2899 & 6.32 & 9.40 \\
\hline Chile (1999) & 1243 & 21.28 & 27.15 & 600 & 7.52 & 8.45 \\
\hline $\begin{array}{c}\text { Colombia } \\
\text { (1999) }\end{array}$ & 1762 & 14.60 & 17.51 & 1115 & 7.76 & 10.15 \\
\hline Costa Rica & 165 & 12.74 & 9.84 & 90 & 6.00 & 3.89 \\
\hline Cuba & 2546 & 38.29 & 53.76 & 1153 & 16.72 & 27.10 \\
\hline Ecuador & 289 & 7.71 & 8.18 & 161 & 3.80 & 4.92 \\
\hline Mexico & 4259 & 14.90 & 15.21 & 2014 & 5.86 & 6.88 \\
\hline Puerto Rico & 399 & 17.52 & 21.07 & 193 & 6.87 & 7.57 \\
\hline Venezuela & 1310 & 18.95 & 25.90 & 796 & 10.11 & 15.80 \\
\hline Canada & 9650 & 43.13 & 50.30 & 6484 & 24.65 & 36.98 \\
\hline USA & 90469 & 46.92 & 57.31 & 65052 & 26.21 & 35.61 \\
\hline \multicolumn{7}{|l|}{ Bone } \\
\hline Argentina & 235 & 1.23 & 1.76 & 175 & 0.69 & 0.81 \\
\hline Brazil (1995) & 430 & 1.00 & 1.23 & 294 & 0.61 & 0.73 \\
\hline
\end{tabular}


Table 2. (Continued)

\begin{tabular}{|c|c|c|c|c|c|c|}
\hline \multirow[t]{2}{*}{ Country } & \multicolumn{3}{|l|}{ Men } & \multicolumn{3}{|l|}{ Women } \\
\hline & $\begin{array}{l}\text { Deaths } \\
\text { no. }\end{array}$ & $\begin{array}{l}\text { World } \\
\text { standard }\end{array}$ & $\begin{array}{l}\text { Truncated } \\
35-64\end{array}$ & $\begin{array}{l}\text { Deaths } \\
\text { no. }\end{array}$ & $\begin{array}{l}\text { World } \\
\text { standard }\end{array}$ & $\begin{array}{l}\text { Truncated } \\
35-64\end{array}$ \\
\hline Chile (1999) & 64 & 0.96 & 0.89 & 57 & 0.69 & 0.32 \\
\hline $\begin{array}{c}\text { Colombia } \\
\text { (1999) }\end{array}$ & 142 & 0.91 & 1.18 & 88 & 0.50 & 0.45 \\
\hline Costa Rica & 15 & 0.96 & 1.03 & 13 & 0.74 & 0.57 \\
\hline Cuba & 82 & 1.27 & 1.97 & 71 & 1.14 & 1.40 \\
\hline Ecuador & 51 & 1.21 & 1.50 & 56 & 1.22 & 1.22 \\
\hline Mexico & 179 & 0.50 & 0.61 & 171 & 0.43 & 0.65 \\
\hline Puerto Rico & 17 & 0.66 & 0.74 & 19 & 0.74 & 0.64 \\
\hline Venezuela & 93 & 1.05 & 1.04 & 65 & 0.73 & 1.04 \\
\hline Canada & 81 & 0.46 & 0.38 & 66 & 0.35 & 0.17 \\
\hline USA & 682 & 0.41 & 0.41 & 530 & 0.26 & 0.22 \\
\hline \multicolumn{7}{|l|}{ Breast } \\
\hline Argentina & & & & 5015 & 20.65 & 37.14 \\
\hline Brazil (1995) & & & & 5831 & 12.45 & 25.04 \\
\hline Chile (1999) & & & & 973 & 12.55 & 22.32 \\
\hline $\begin{array}{c}\text { Colombia } \\
\text { (1999) }\end{array}$ & & & & 1434 & 9.46 & 19.09 \\
\hline Costa Rica & & & & 182 & 11.85 & 24.28 \\
\hline Cuba & & & & 1012 & 14.82 & 28.22 \\
\hline Ecuador & & & & 287 & 6.97 & 14.10 \\
\hline Mexico & & & & 3468 & 9.90 & 21.27 \\
\hline Puerto Rico & & & & 338 & 13.75 & 27.96 \\
\hline Venezuela & & & & 1107 & 13.34 & 27.17 \\
\hline Canada & & & & 4857 & 18.24 & 32.60 \\
\hline USA & & & & 41872 & 17.56 & 31.95 \\
\hline \multicolumn{7}{|l|}{ Uterus } \\
\hline Argentina & & & & 2422 & 10.68 & 21.49 \\
\hline Brazil (1995) & & & & 4379 & 9.27 & 17.88 \\
\hline Chile (1999) & & & & 908 & 11.58 & 19.43 \\
\hline $\begin{array}{c}\text { Colombia } \\
\text { (1999) }\end{array}$ & & & & 2126 & 13.93 & 27.20 \\
\hline Costa Rica & & & & 174 & 11.60 & 18.04 \\
\hline Cuba & & & & 958 & 14.13 & 28.09 \\
\hline Ecuador & & & & 627 & 14.72 & 26.50 \\
\hline Mexico & & & & 5198 & 14.82 & 28.36 \\
\hline Puerto Rico & & & & 119 & 4.88 & 9.07 \\
\hline Venezuela & & & & 1437 & 16.92 & 30.77 \\
\hline Canada & & & & 1038 & 3.79 & 6.14 \\
\hline USA & & & & 10786 & 4.59 & 7.92 \\
\hline \multicolumn{7}{|l|}{ Ovary } \\
\hline Argentina & & & & 1133 & 4.74 & 8.73 \\
\hline Brazil (1995) & & & & - & - & - \\
\hline Chile (1999) & & & & 318 & 4.21 & 7.63 \\
\hline $\begin{array}{c}\text { Colombia } \\
\text { (1999) }\end{array}$ & & & & 456 & 3.08 & 5.60 \\
\hline Costa Rica & & & & 50 & 3.50 & 6.15 \\
\hline
\end{tabular}

Table 2. (Continued)

\begin{tabular}{|c|c|c|c|c|c|}
\hline \multirow[t]{2}{*}{ Country } & \multicolumn{2}{|l|}{ Men } & \multicolumn{3}{|c|}{ Women } \\
\hline & $\begin{array}{l}\text { Deaths } \\
\text { no. }\end{array}$ & $\begin{array}{l}\text { World Truncated } \\
\text { standard } 35-64\end{array}$ & $\begin{array}{l}\text { Deaths } \\
\text { no. }\end{array}$ & $\begin{array}{l}\text { World } \\
\text { standard }\end{array}$ & $\begin{array}{l}\text { Truncate } \\
35-64\end{array}$ \\
\hline Cuba & & & 218 & 3.35 & 6.85 \\
\hline Ecuador & & & 98 & 2.26 & 4.04 \\
\hline Mexico & & & 1186 & 3.44 & 6.39 \\
\hline Puerto Rico & & & 79 & 2.93 & 4.39 \\
\hline Venezuela & & & 305 & 3.64 & 5.92 \\
\hline Canada & & & 1429 & 5.34 & 8.41 \\
\hline USA & & & 14453 & 5.84 & 9.04 \\
\hline
\end{tabular}

Prostate

$\begin{array}{lrrr}\text { Argentina } & 3510 & 16.28 & 6.48 \\ \text { Brazil (1995) } & 4380 & 11.95 & 6.11 \\ \text { Chile (1999) } & 1224 & 19.85 & 5.44 \\ \text { Colombia } & 1828 & 14.54 & 6.64 \\ \quad \text { (1999) } & & & \\ \text { Costa Rica } & 282 & 21.70 & 4.58 \\ \text { Cuba } & 1844 & 23.06 & 10.49 \\ \text { Ecuador } & 580 & 15.32 & 5.26 \\ \text { Mexico } & 3852 & 13.14 & 5.62 \\ \text { Puerto Rico } & 524 & 17.49 & 6.77 \\ \text { Venezuela } & 1408 & 22.26 & 8.60 \\ \text { Canada } & 3718 & 13.86 & 5.10 \\ \text { USA } & 31078 & 12.73 & 5.27\end{array}$

Testis

\begin{tabular}{|c|c|c|c|c|c|c|}
\hline Argentina & 132 & 0.71 & 0.78 & & & \\
\hline Brazil (1995) - & & & - & & & \\
\hline Chile (1999) & 105 & 1.30 & 1.55 & & & \\
\hline $\begin{array}{c}\text { Colombia } \\
\text { (1999) }\end{array}$ & 77 & 0.40 & 0.40 & & & \\
\hline Costa Rica & 12 & 0.68 & 0.70 & & & \\
\hline Cuba & 17 & 0.28 & 0.33 & & & \\
\hline Ecuador & 25 & 0.48 & 0.61 & & & \\
\hline Mexico & 311 & 0.66 & 0.60 & & & \\
\hline Puerto Rico & 6 & 0.28 & 0.16 & & & \\
\hline Venezuela & 37 & 0.36 & 0.47 & & & \\
\hline Canada & 37 & 0.20 & 0.26 & & & \\
\hline USA & 338 & 0.21 & 0.32 & & & \\
\hline \multicolumn{7}{|l|}{ 3ladder } \\
\hline Argentina & 944 & 4.61 & 4.03 & 318 & 1.04 & 0.86 \\
\hline Brazil (1995) & 979 & 2.64 & 2.11 & 431 & 0.90 & 0.92 \\
\hline Chile (1999) & 152 & 2.51 & 1.84 & 94 & 1.09 & 0.75 \\
\hline $\begin{array}{c}\text { Colombia } \\
\text { (1999) }\end{array}$ & 204 & 1.61 & 1.34 & 113 & 0.77 & 0.71 \\
\hline Costa Rica & 35 & 2.76 & 1.38 & 15 & 0.98 & 0.75 \\
\hline Cuba & 306 & 4.00 & 3.05 & 96 & 1.15 & 0.93 \\
\hline Ecuador & 36 & 0.98 & 0.44 & 29 & 0.63 & 0.28 \\
\hline Mexico & 398 & 1.38 & 1.08 & 220 & 0.62 & 0.57 \\
\hline Puerto Rico & 65 & 2.53 & 2.28 & 37 & 1.12 & 0.96 \\
\hline
\end{tabular}


Table 2. (Continued)

\begin{tabular}{|c|c|c|c|c|c|c|}
\hline \multirow[t]{2}{*}{ Country } & \multicolumn{3}{|l|}{ Men } & \multicolumn{3}{|l|}{ Women } \\
\hline & $\begin{array}{l}\text { Deaths } \\
\text { no. }\end{array}$ & $\begin{array}{l}\text { World } \\
\text { standard }\end{array}$ & $\begin{array}{l}\text { Truncated } \\
35-64\end{array}$ & $\begin{array}{l}\text { Deaths } \\
\text { no. }\end{array}$ & $\begin{array}{l}\text { World } \\
\text { standard }\end{array}$ & $\begin{array}{l}\text { Truncated } \\
35-64\end{array}$ \\
\hline Venezuela & 125 & 1.89 & 1.62 & 61 & 0.75 & 0.50 \\
\hline Canada & 1082 & 4.34 & 3.17 & 437 & 1.20 & 0.92 \\
\hline USA & 8163 & 3.65 & 2.83 & 3839 & 1.15 & 0.95 \\
\hline \multicolumn{7}{|l|}{ Leukemia } \\
\hline Argentina & 969 & 4.96 & 4.95 & 764 & 3.20 & 3.32 \\
\hline Brazil (1995) & 1554 & 3.61 & 4.23 & 1340 & 2.76 & 3.43 \\
\hline Chile (1999) & 282 & 4.29 & 4.72 & 252 & 3.22 & 3.38 \\
\hline $\begin{array}{c}\text { Colombia } \\
\text { (1999) }\end{array}$ & 766 & 4.52 & 4.39 & 656 & 3.58 & 4.10 \\
\hline Costa Rica & 82 & 5.20 & 4.82 & 55 & 3.29 & 3.77 \\
\hline Cuba & 268 & 4.36 & 4.95 & 223 & 3.35 & 4.69 \\
\hline Ecuador & 225 & 4.23 & 4.66 & 150 & 2.73 & 3.62 \\
\hline Mexico & 1739 & 4.20 & 4.18 & 1562 & 3.54 & 4.20 \\
\hline Puerto Rico & 95 & 4.02 & 4.59 & 85 & 3.15 & 4.62 \\
\hline Venezuela & 410 & 4.31 & 4.02 & 335 & 3.31 & 3.97 \\
\hline Canada & 1190 & 5.40 & 5.12 & 858 & 2.92 & 2.90 \\
\hline USA & 11777 & 5.94 & 5.56 & 9562 & 3.58 & 3.80 \\
\hline \multicolumn{7}{|l|}{ All neoplasms } \\
\hline Argentina & 30253 & 153.52 & 191.32 & 25237 & 98.65 & 147.22 \\
\hline Brazil (1995) & 44774 & 116.97 & 158.76 & 37110 & 78.78 & 119.74 \\
\hline Chile (1999) & 9426 & 155.98 & 154.46 & 9151 & 113.65 & 147.60 \\
\hline $\begin{array}{c}\text { Colombia } \\
\text { (1999) }\end{array}$ & 13343 & 103.72 & 116.20 & 13588 & 89.41 & 130.13 \\
\hline Costa Rica & 1662 & 123.81 & 109.22 & 1431 & 93.74 & 117.16 \\
\hline Cuba & 9536 & 138.71 & 170.93 & 7270 & 102.86 & 160.58 \\
\hline Ecuador & 3346 & 84.86 & 79.73 & 3584 & 82.62 & 118.51 \\
\hline Mexico & 27841 & 91.18 & 96.02 & 29940 & 84.18 & 127.47 \\
\hline Puerto Rico & 2766 & 115.95 & 141.47 & 2092 & 75.30 & 105.28 \\
\hline Venezuela & 8217 & 116.53 & 124.82 & 7993 & 96.47 & 143.23 \\
\hline Canada & 34096 & 148.33 & 163.07 & 30015 & 105.71 & 146.53 \\
\hline USA & 292641 & 146.41 & 172.04 & 273996 & 105.38 & 146.26 \\
\hline
\end{tabular}

countries of the Americas for 5-year calendar periods from 1970-1974 to 1995-99 and year 2000, for men and women. Different scales were adopted for each neoplasm and country, in order to provide more easily readable and interpretable patterns.

\section{Mouth and pharynx}

In the year 2000, the highest rates for oral and pharyngeal cancer mortality in men were observed in Brazil, Cuba and Puerto Rico with values around 5-6/100000, i.e. 1.5- to 2.0fold higher than values from Canada and the USA. Colombia, Ecuador and Mexico showed the lowest rates, with values around 1-2/100000. As in Canada, the USA and several countries of Europe [1], a leveling or even a fall in mortality rates from oral and pharyngeal cancer was observed in various Latin American countries, starting from the 1970s in Puerto Rico and Venezuela, since the early 1980s in Argentina and Chile, and since the late 1980s in Colombia. In Mexico, mortality from cancers of the mouth and pharynx in men increased between 1970 and 1989, and leveled off thereafter. In Cuba, after a favorable trend between 1970 and 1985, rates have started to increase again, notwithstanding a nationwide screening program implemented for a number of years [17]. No clear trend was observed in Costa Rica and Ecuador. Mortality rates for cancer of the mouth and pharynx in women were very low (between 0.5 and 1.5/100000) and showed no appreciable trends in any country, except in Venezuela, where rates continuously declined between the 1970s (characterized by particularly high rates) and the 1980 s, and tended to level off thereafter.

Since alcohol drinking and tobacco smoking are the major risk factors for cancer of the mouth and pharynx [18-21], recent favorable trends in mortality in most American countries would indicate favorable changes in the exposure to these two risk factors over the last decades [22]. Additional factors, mainly related to improvement in diet [23] and maté drinking — particularly in Argentina and Brazil [24]—may also have had some role on recent trends.

\section{Esophagus}

In 2000, Argentina, Brazil, Chile and Puerto Rico had the highest rates for male esophageal cancer mortality (values about 7-8/100000). The same countries were also characterized by high esophageal mortality in women (values between 2 and 3/100 000). Ecuador and Mexico showed very low mortality rates from esophageal cancer in both sexes. In some of the high risk countries, rates steadily declined in both sexes in the last three decades. Similar decreasing trends were found in most other Latin American countries, including Venezuela, which started from high rates in the 1970s, Colombia, Costa Rica and Ecuador, where the decline started since the late 1980s. In Cuba and Mexico, as well as in Canada and the USA, upward trends in rates were observed in men, but not in women.

In most countries, mortality patterns were similar for esophageal and oral and pharyngeal cancers, underlining similarities of risk factors for these two neoplasms, i.e. alcohol drinking and tobacco smoking [18, 19, 21], plus maté drinking [25] and other dietary items [23]. The rising trends observed in the last decades in Canada and in the USA are probably due to an increased incidence and mortality from adenocarcinoma of the esophagus, associated with overweight, obesity and gastro-esophageal reflux besides tobacco smoking, but not to alcohol drinking [26-28].

\section{Stomach}

Over recent calendar periods, male stomach cancer mortality was exceedingly high in some Latin American countries, including Chile, Costa Rica and Ecuador (with rates higher 
than 20/100 000), Argentina, Brazil, Colombia and Venezuela (with rates between 10 and 20/100000 in men). Only Cuba, Mexico and Puerto Rico had male rates lower than 10/100 000, but still higher than those in Canada (5.2/100 000) and the USA (3.7/100000). Stomach cancer mortality in women was lower than in men, but the geographical differences were similar to those in men. Thus, rates were higher in Chile, Costa Rica and Ecuador (over 12/100 000), and lower in Argentina, Cuba and Puerto Rico (below 4/100 000). Corresponding figures in Canada and the USA were 2.6/100000 and $1.8 / 100000$, respectively.

Mortality from stomach cancer continued to steadily decrease in the last three decades in most countries of Latin America, including Colombia and Ecuador, where rates showed increasing trends up to the 1980s. The reasons for the generalized favorable patterns in gastric cancer rates in these countries, as well as in the USA [4], Europe [1] and elsewhere in the world, are not completely understood, but almost certainly include better food conservation-including refrigeration-a more varied and affluent diet [23, 29, 30], reduced prevalence of Helicobacter pylori infection [31-33], and a possible reduction in tobacco smoking, at least in men [34]. However, mortality from stomach cancer is still extremely high in several Latin American countries, underlining the importance of continuous monitoring and effort in the prevention of this malignancy.

\section{Intestines, chiefly colon and rectum}

Mortality rates from cancer of the intestines in 2000 were below 10/100 000 in most countries of Latin America, the only exceptions being Argentina and Puerto Rico, where men had rates of 14.9 and 11.9/100000, respectively, and Cuba where men had rates of 10.5/1000 and women of 12.8/100000. Corresponding values in Canada and the USA were around $14-15 / 100000$ in men and around 10/100000 in women. While in Canada and the USA mortality from colorectal cancer showed continuous downward trends in the last three decades [35], the pattern of colorectal cancer mortality in other countries of the Americas was less favorable. In Argentina, after a decline between the 1970s and the 1980s [36], rates were stable, or even slightly increasing, in the two last decades. Increasing colorectal cancer mortality has also been observed in several other countries of Latin America.

The low rates for colorectal cancer in countries like Brazil, Colombia and Mexico, if not due to substantial underreporting, likely reflect long-term favorable dietary habits in these countries. However, patterns of colorectal cancer mortality are unfavorable in these, as in other countries of Latin America, probably as a consequence of modifications in dietary and lifestyle habits, including an increase in the prevalence of overweight and obesity [37-39]. The relatively high colorectal cancer mortality in Argentina is consistent with a role of red meat (frequently consumed in this country) on colorectal carcinogenesis [23]. In Cuba, as in Costa Rica and Ecuador, colorectal cancer mortality rates (both all ages and truncated) were higher in women than in men, but there is no satisfactory explanation for the peculiar sex ratio in these countries [40, 41]. It appears that Cuban women not only have higher rates of tobacco- (and alcohol-) related neoplasms, but also of colorectal cancer, which is moderately associated with alcohol and tobacco consumption, but is probably related to nutrition and diet [42].

\section{Larynx}

In 2000, male mortality from laryngeal cancer was high in Argentina, Brazil and Cuba, with rates between 4 and 7/100000 men, whereas countries with lower mortality were Chile, Costa Rica and Ecuador, with rates between 0.9 and $1.7 / 100000$, i.e. similar to those reported in Canada and the USA. Declines in mortality rates were observed in Argentina, Chile, particularly in middle-aged men, Ecuador, and Puerto Rico. A similar decrease in rates was observed in the USA since the early 1970s, and in Canada since the late 1980s. A steady upward trend since the late 1980s was observed in men from Cuba and Venezuela, particularly in middle-aged ones. The pattern in laryngeal cancer mortality was less clear in other countries. Female rates were extremely low (between 0.1 and 0.7/100000) in most American countries (except Cuba, with a value of 1.2/100000), and their trends were unremarkable.

This is another neoplasm strongly related to tobacco smoking and alcohol consumption [19], and its trends are consistent, although somewhat less favorable, with those for oral, pharyngeal and esophageal cancer, probably reflecting the predominant role of tobacco on laryngeal carcinogenesis [21]. Rates in Canada, and particularly in the USA, were lower than in Latin American countries, as a consequence of a decrease in tobacco consumption in men in the last decades [22]. Modern low tar yield cigarettes, which are deeply inhaled, are also associated with lower laryngeal cancer risk, compared to older ones [43]. Rates in Cuba, which are among the highest on a worldwide scale [2] can also be related to cigar [44], and consequently to black tobacco smoking [43, 45, 46].

\section{Trachea, bronchus and lung}

In 2000, lung cancer mortality rates in men were much lower in most Latin American countries (rates between 13 and 21/100000) than in North America (rates over 40/100000). The highest rates for men were registered in Argentina and Cuba (35.0 and 38.3/100000, respectively), whereas the lowest rate was observed in Ecuador (7.7/100 000). In Argentina, rates have steadily, though moderately, decreased in the last three decades and are now lower than in the 1970s [36]. Conversely, in Cuba trends were stable overall, and slightly increasing in middle-aged men. In other Latin American countries, mortality from lung cancer, after a steady increase up to the 1980s [47], showed a tendency to level off in the last two decades, and even to decrease in middle-aged adults. Only in Ecuador and Venezuela, are rates in lung cancer mortality are still increasing. In the USA and Canada, substantial declines were observed in overall lung cancer rates over 

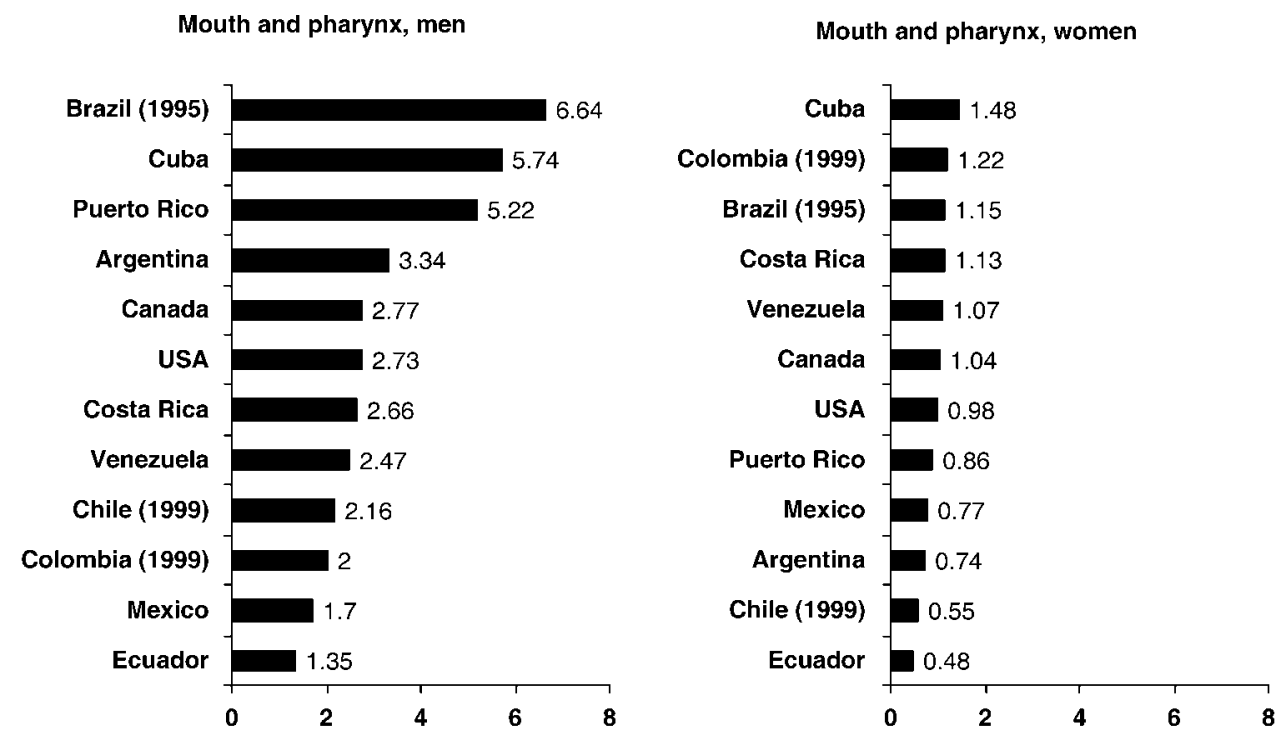

Oesophagus, men

Oesophagus, women
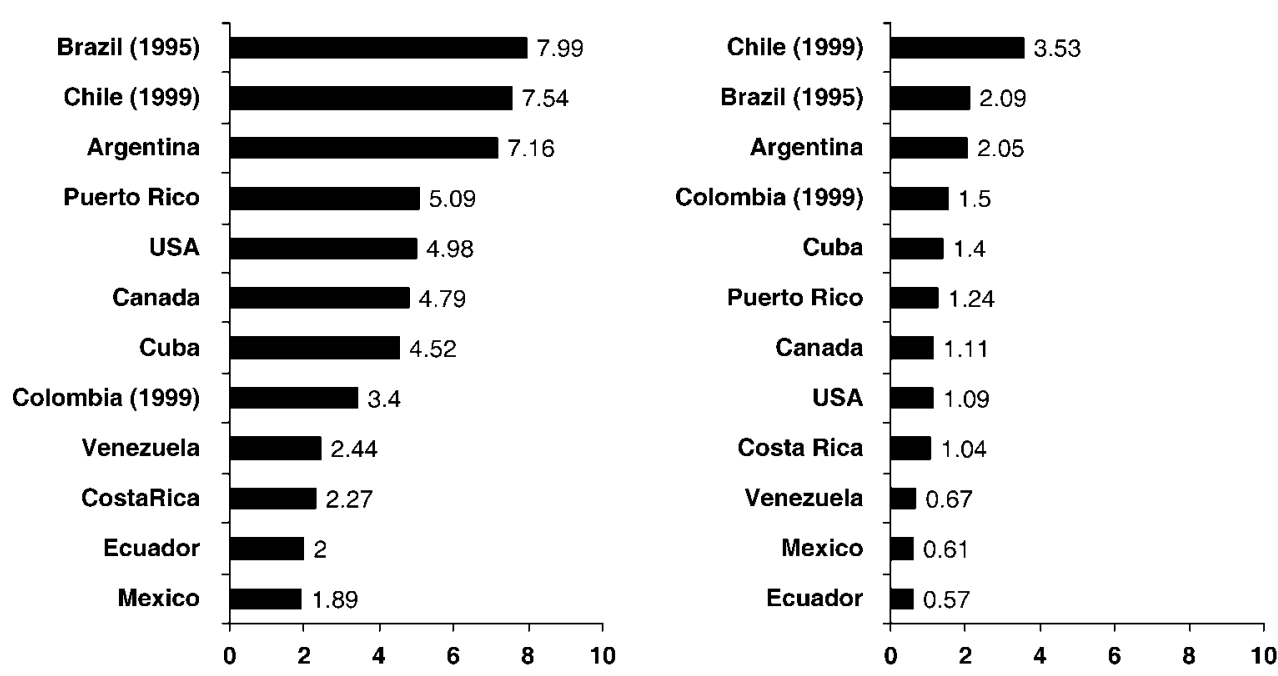

Stomach, men

Stomach, women
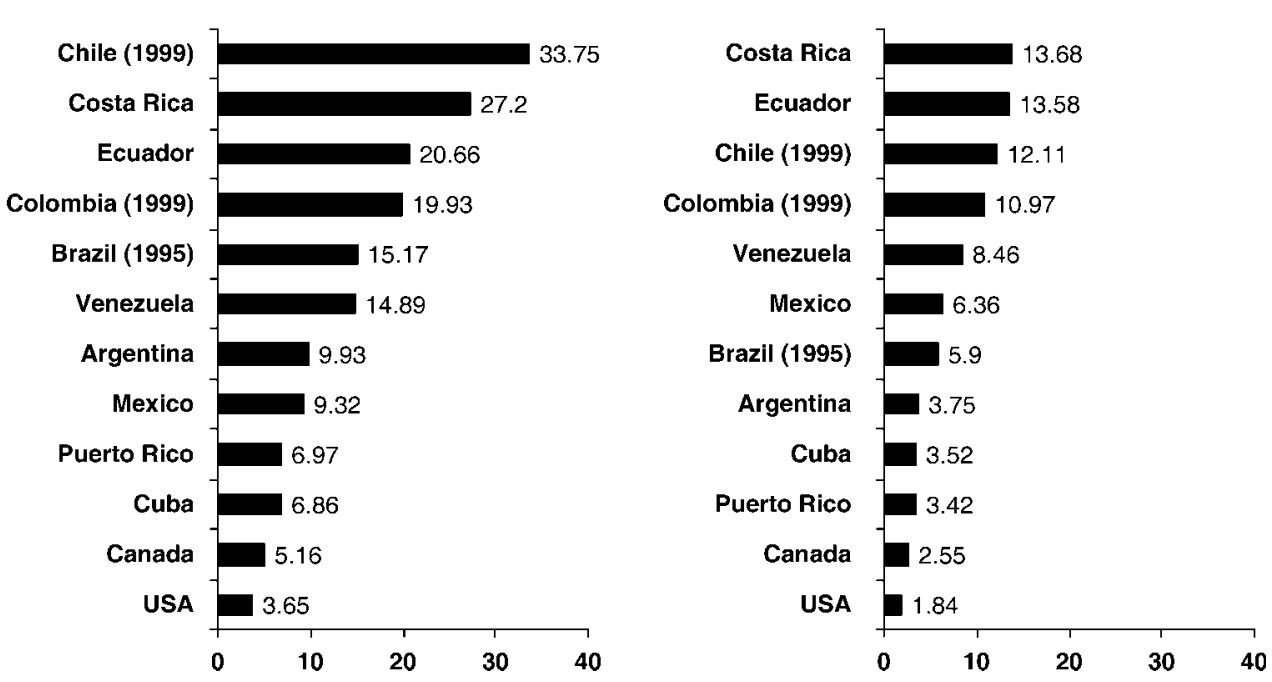

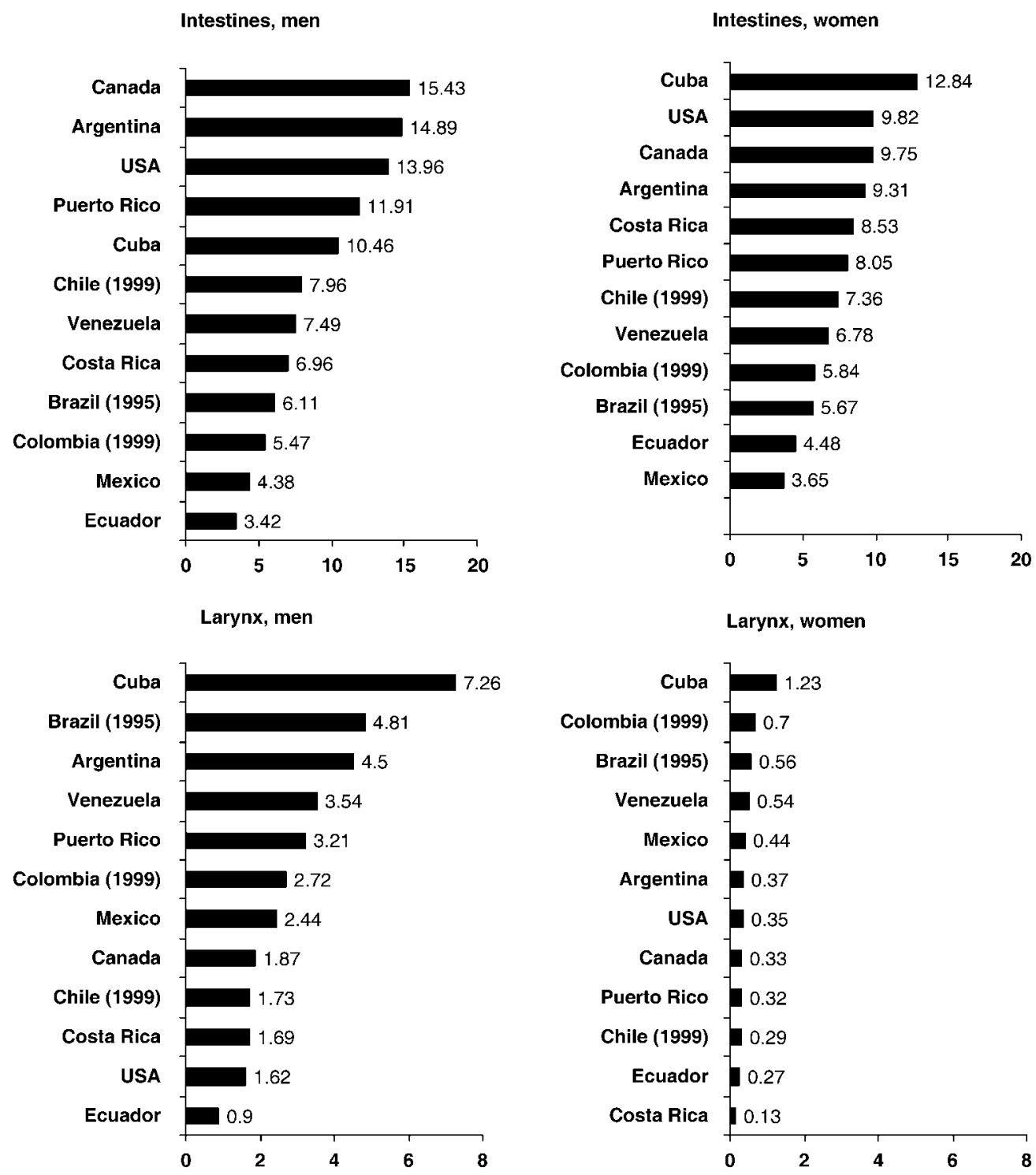

Lung, men

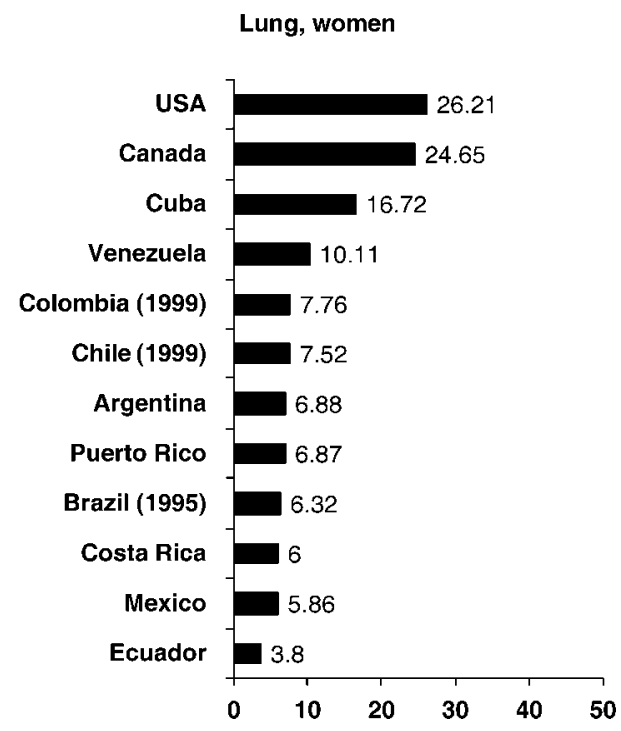



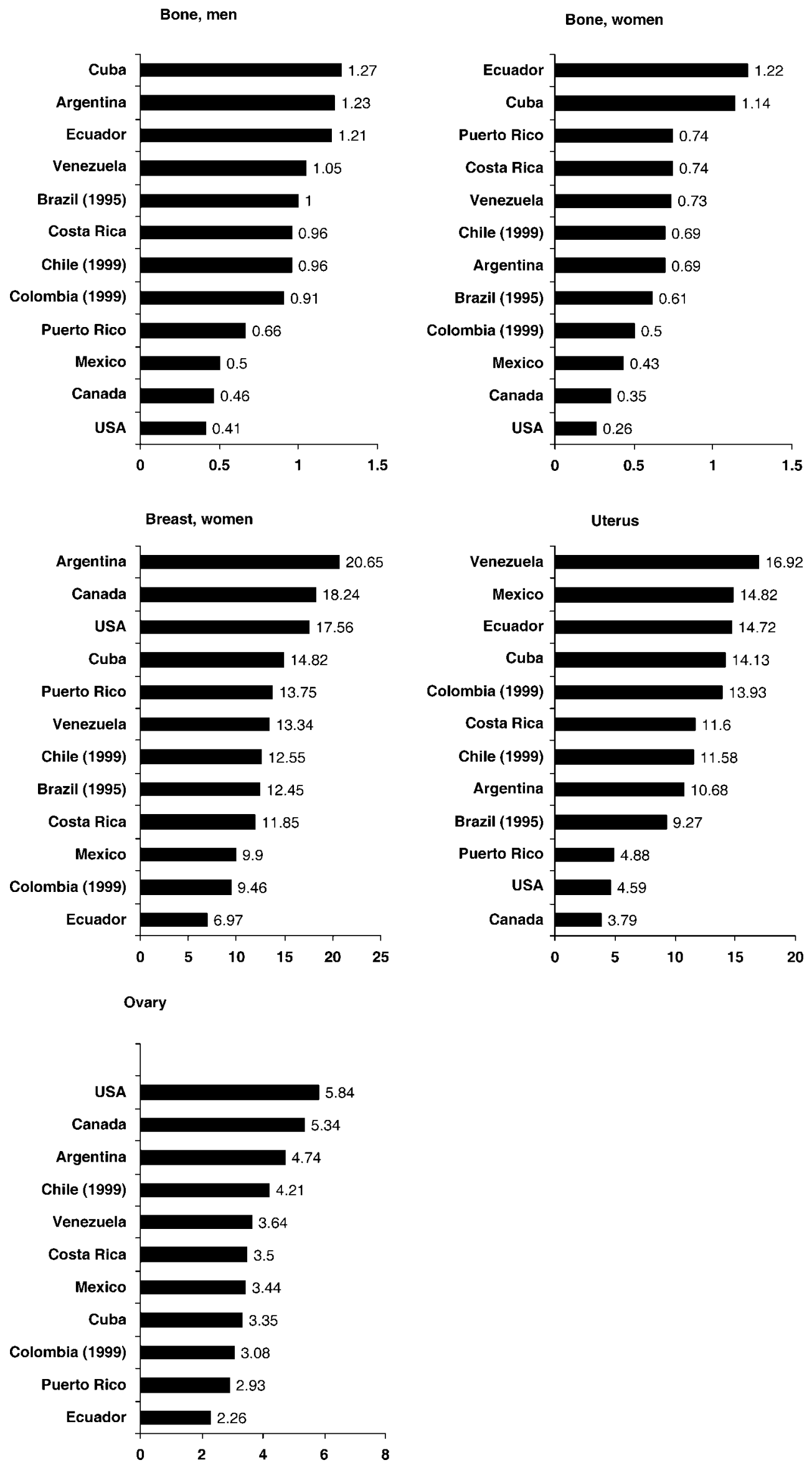
Prostate

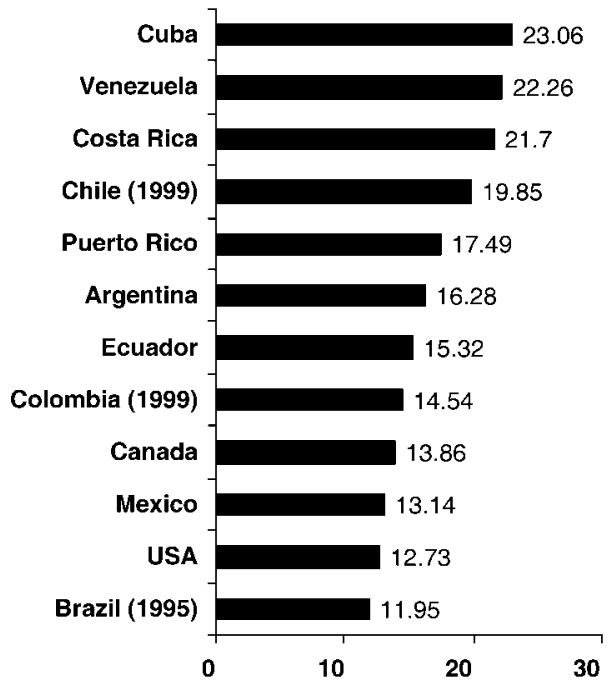

Bladder, men

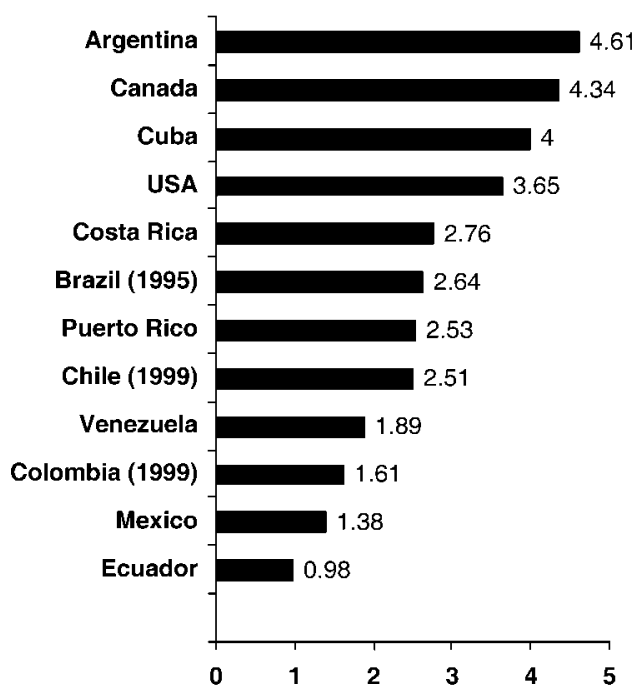

Leukemias, men

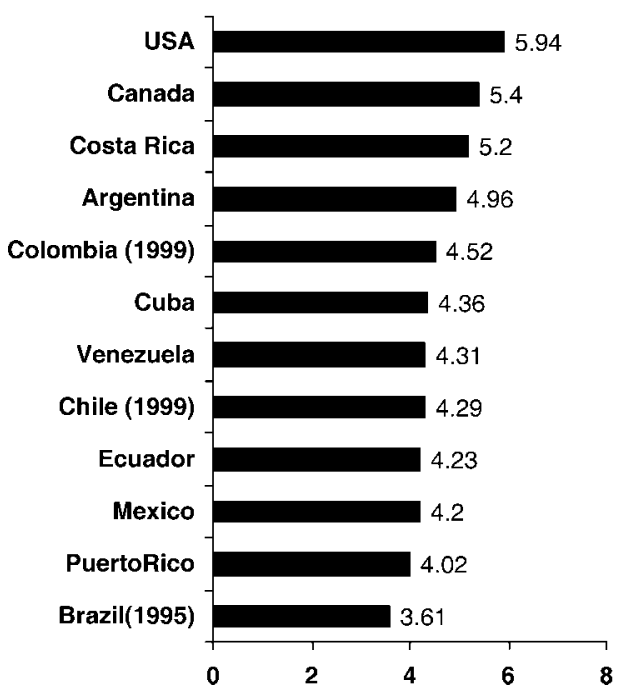

Testis

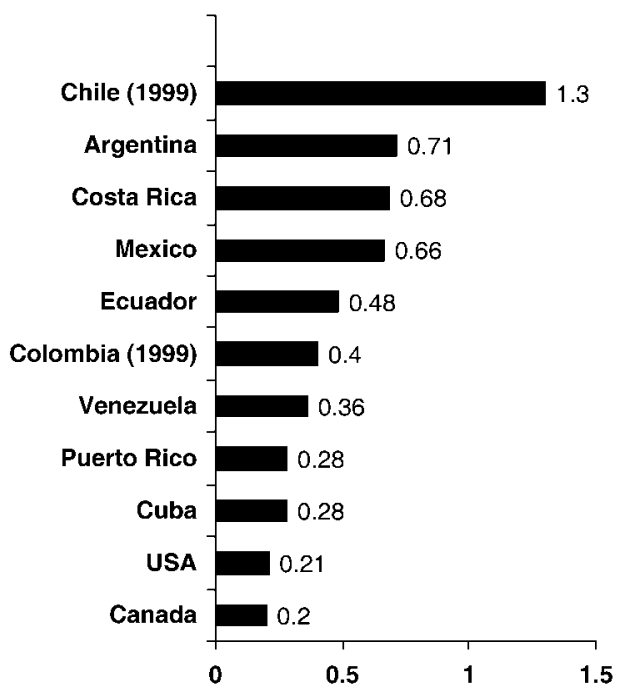

Bladder, women

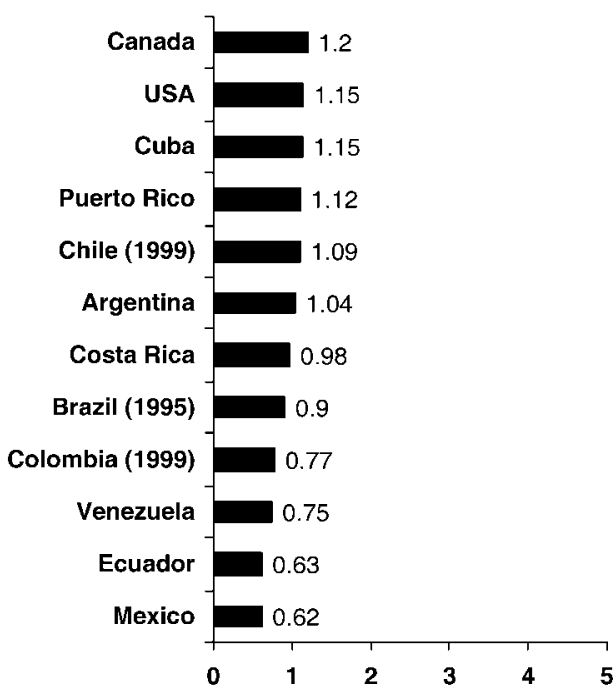

Leukemias, women

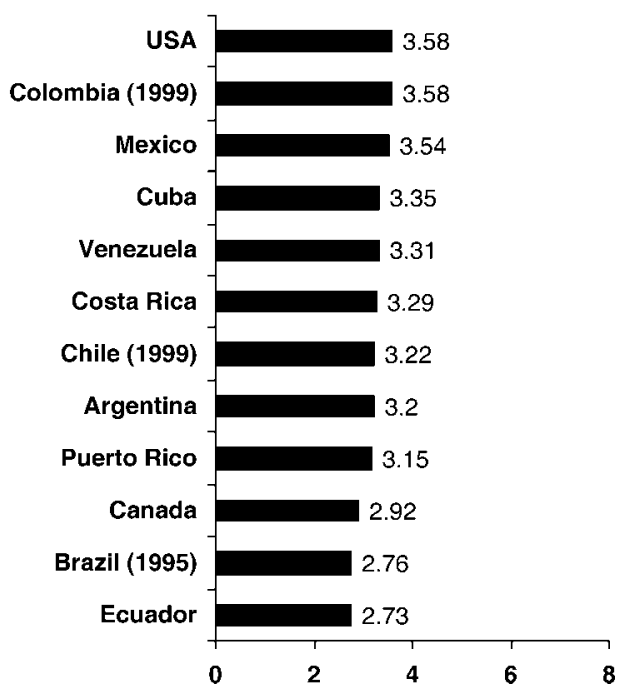


All neoplasms, men

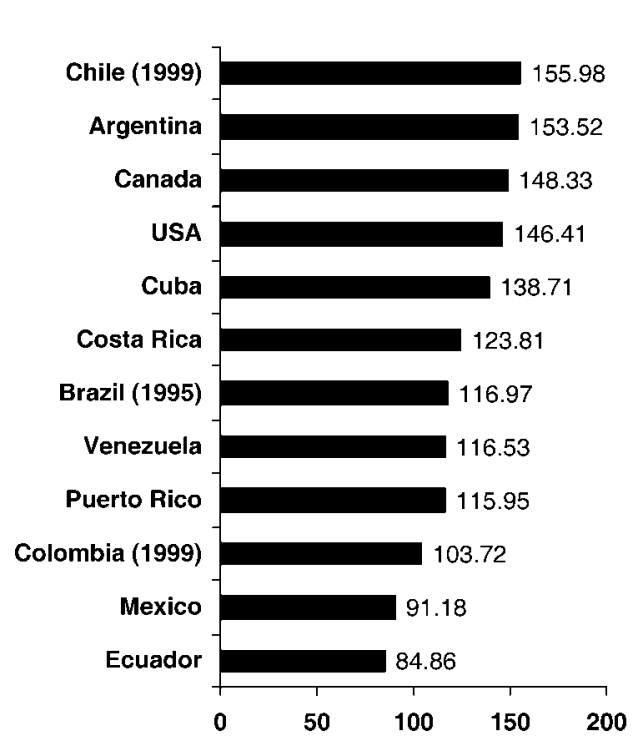

All neoplasms, women

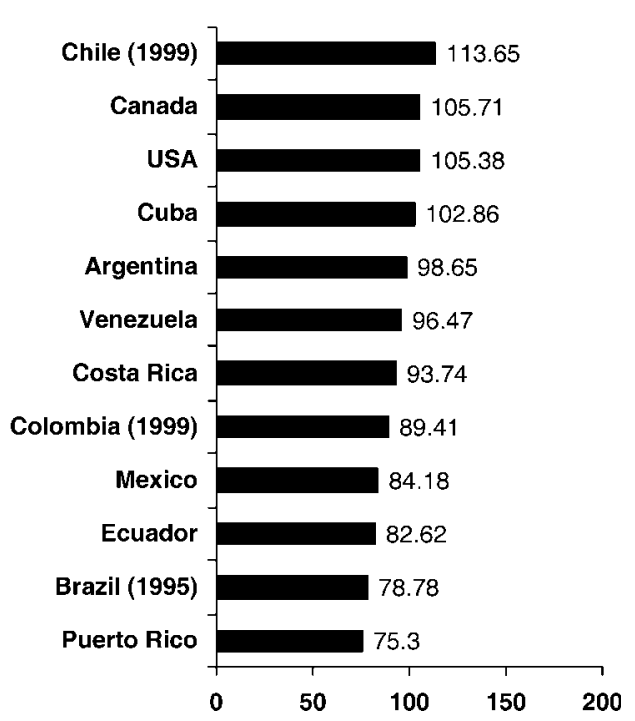

Figure 1. Age-standardized (world population) death rates per 100000 from 14 cancer sites plus total cancer mortality in selected countries of the Americas in 2000 (unless mentioned in parentheses).

the last two decades, and even greater declines in middle-aged adults since the early 1990s [48, 49]. Female lung cancer rates, in most Latin American countries, were still below 10/100000, i.e. substantially lower than in North American women (rates over 20/100000), with the only exception of Cuba (16.7/100 000). In several countries of Latin America, as in the USA [50], lung cancer mortality in women has, however, been increasing over the last decades [51].

Since the lung is the most important tobacco-related cancer site, these trends essentially reflect smoking habits of subsequent generations of men and women in various American countries [22]. Thus, while in men they probably reflect a decline in tobacco smoking in several countries, the persistent comparatively low rates in women from most Latin American countries indicate the scope of the intervention in tobacco control, to avoid a major lung cancer epidemic in Latin American women in the near future. Occupational, mainly asbestos control, environmental and perhaps dietary factors of lung cancer may also have exerted some influences on these favorable trends in men [52].

\section{Bone}

Mortality rates from bone cancer were higher in most countries in Latin America than they were in Canada and the USA, with rates around 1/100000 in men and slightly lower in women. Since bone is one of the commonest sites of metastasis [15], this may reflect less accurate death certification in several Latin American countries compared with North America. Mortality trends for bone neoplasms are therefore difficult to interpret, but a general tendency to decline can be observed in various Latin American countries, as in Canada and the USA, probably reflecting improvements in accuracy and validity of death certification over recent calendar periods.

\section{Breast}

Female breast cancer mortality in 2000 was highest in Argentina (20.7/100000), with rates higher than those reported in North America (i.e. around 18/100000). In all other Latin American countries, rates were around 12-15/100000, with the exception of Colombia, Ecuador and Mexico, where rates were below 10/100000. Trends in mortality rates over the last decades were stable in Argentina, Chile and Cuba, while they were increasing in other Latin American countries, particularly those characterized by originally lower mortality. Conversely, in North America, breast cancer mortality has been steadily declining, particularly in middle-aged women, in the last two decades [53, 54].

The increase in female breast cancer trends is likely to be related to changes in reproductive habits of subsequent cohorts of American women, and in particular to a decreased fertility [55]. Changes in dietary habits and other lifestyle factors [56], and increased overweight [37] may also have played some role in the recent upward trends in breast cancer. The declines in breast cancer mortality in North America, together with the stable rates in high and intermediate mortality areas from Latin America, and the systematic upwards trends in the low mortality ones indicate that rates tend to level off across the Americas, probably as a consequence of a general tendency towards more uniform reproductive and lifestyle habits. The falls in breast cancer mortality observed in Canada and the USA, as well as in European countries [1], are probably attributable to advancements in therapy, including the widespread use of tamoxifen and adjuvant chemotherapy [57-59], although some role of (mammographic) screening is also possible [60].

\section{Uterus (cervix and corpus)}

On the basis of death certification, it is not possible to distinguish cancers arising from cervix and from the corpus uteri 
(a)
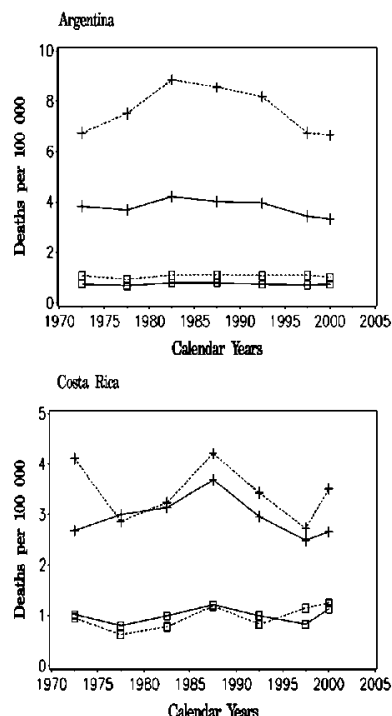

Calendar Years

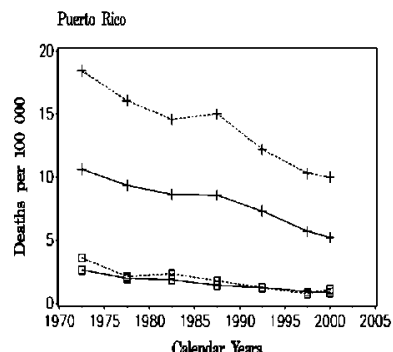

Calendar Years

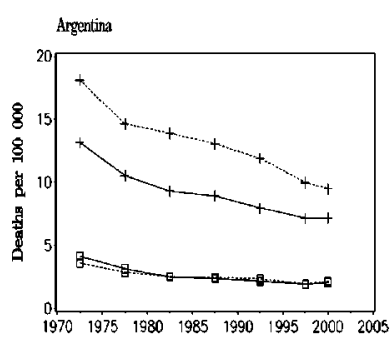

Calendar Years
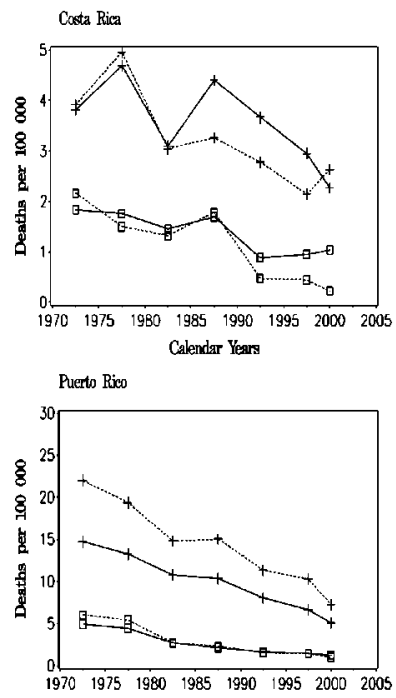

Calendar Years
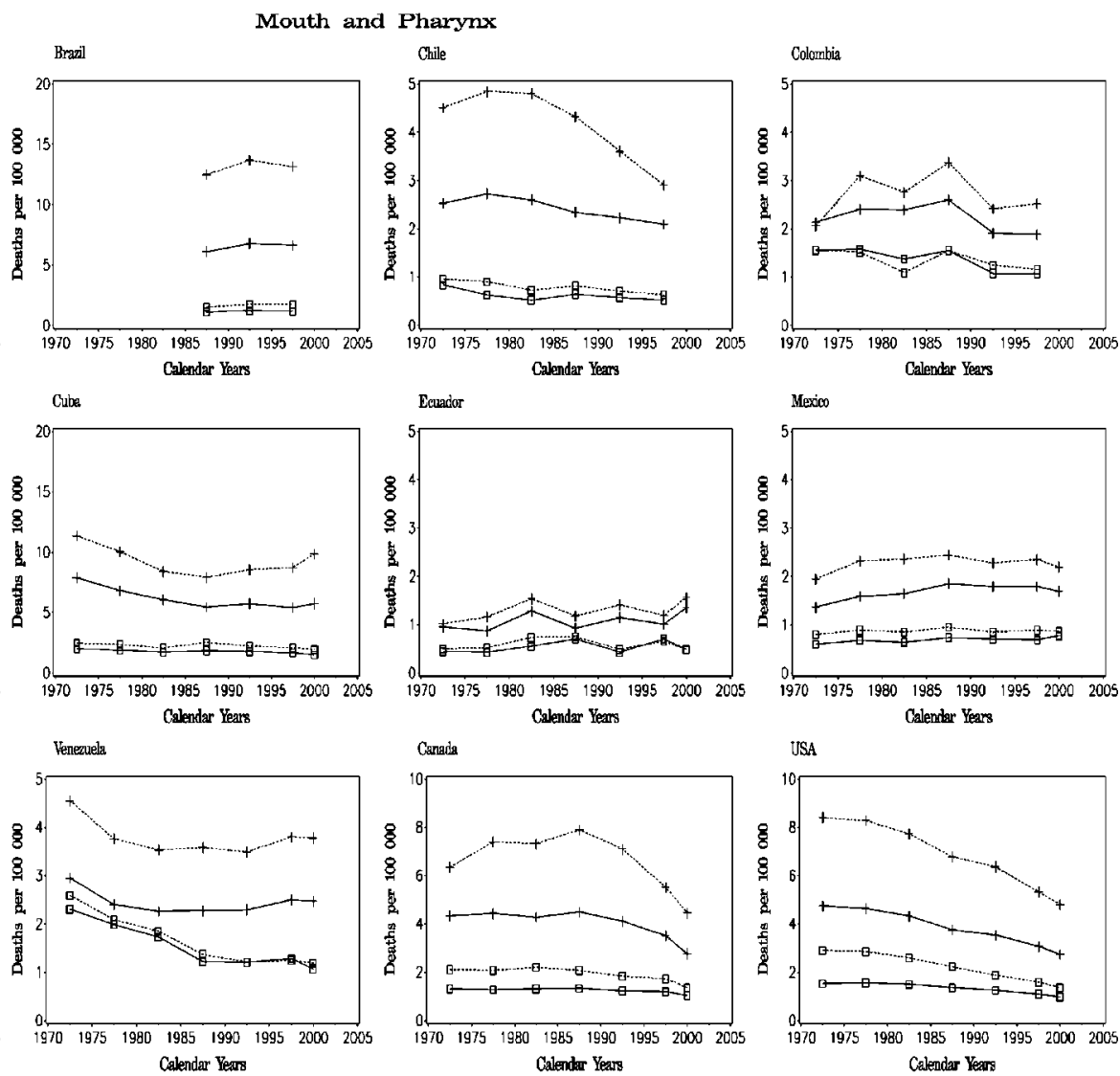

Calendar Years

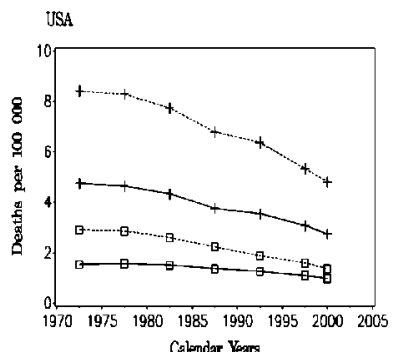

Oesophagus
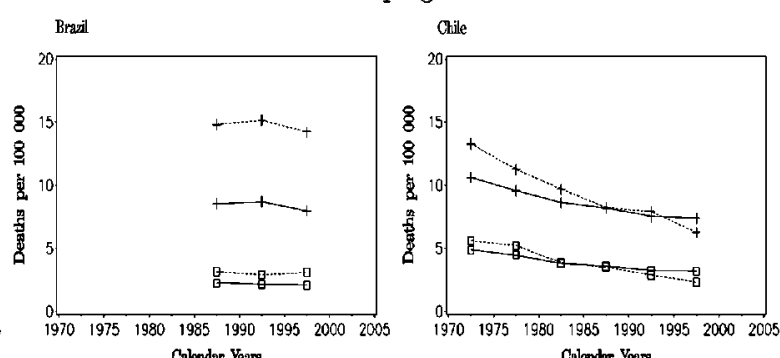
Calender Years
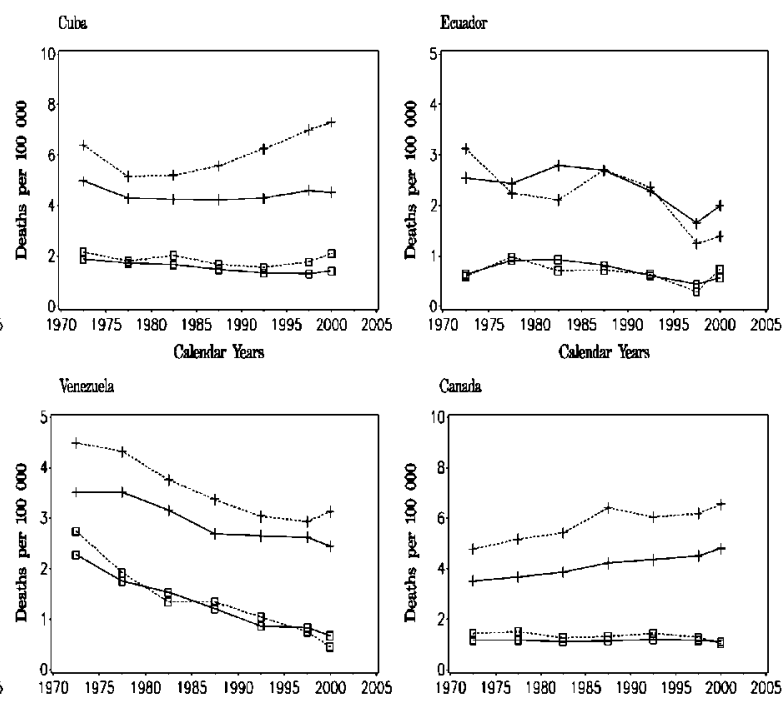

Calendar Years Calendar Years

$\begin{array}{lllllllll}0 & 1970 & 1975 & 1980 & 1985 & 1990 & 1995 & 2000 & 2005\end{array}$

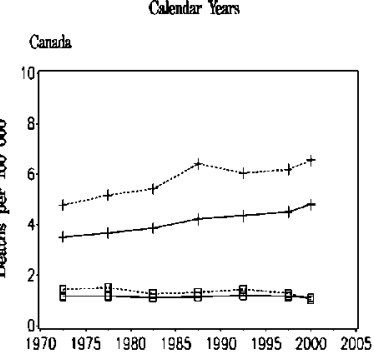

Calcentar Years

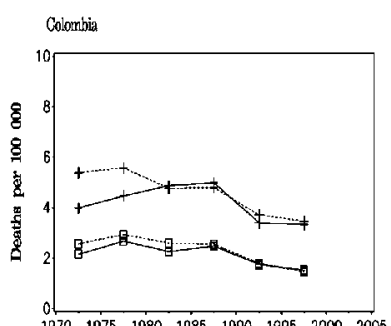

$\begin{array}{lllllllll}1970 & 1975 & 1980 & 1985 & 1990 & 1995 & 2000 & 2005\end{array}$ Calendar Years
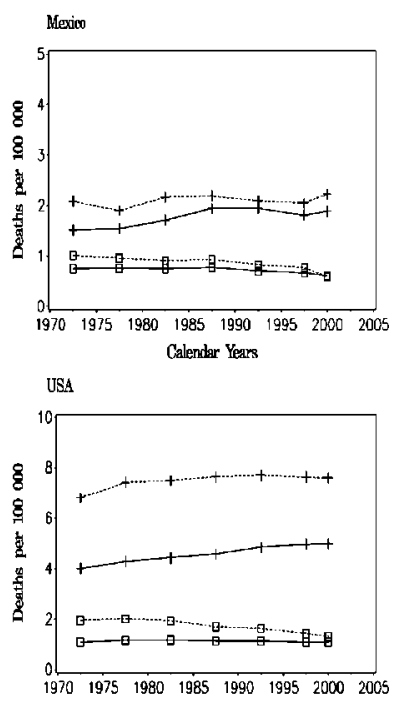

Calendar Yrars 
(b)
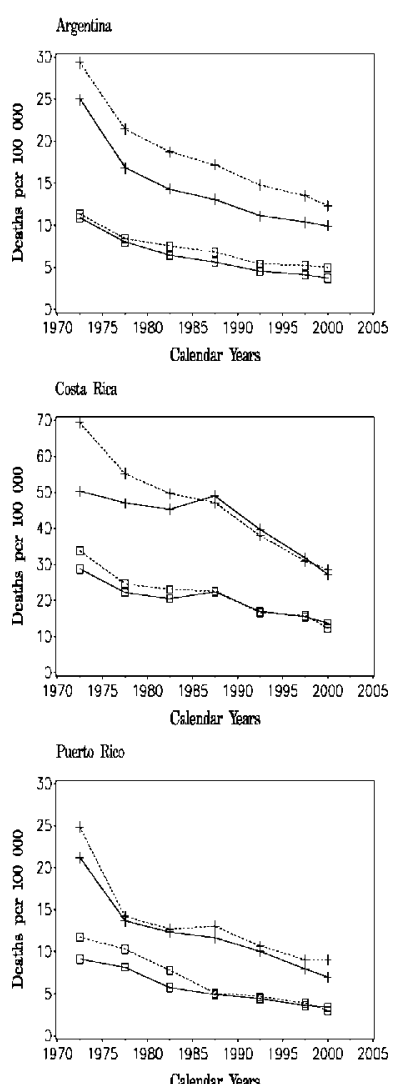

Calendar Years

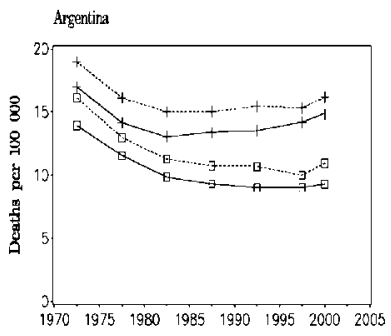

Calendar Years

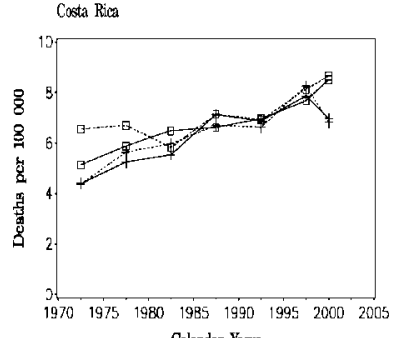

Calendar Years

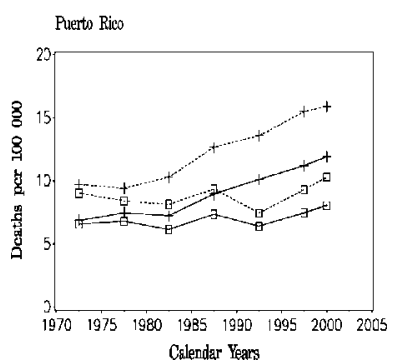

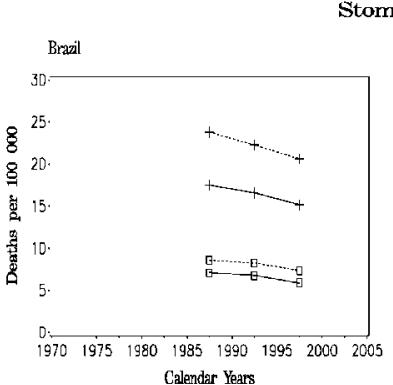
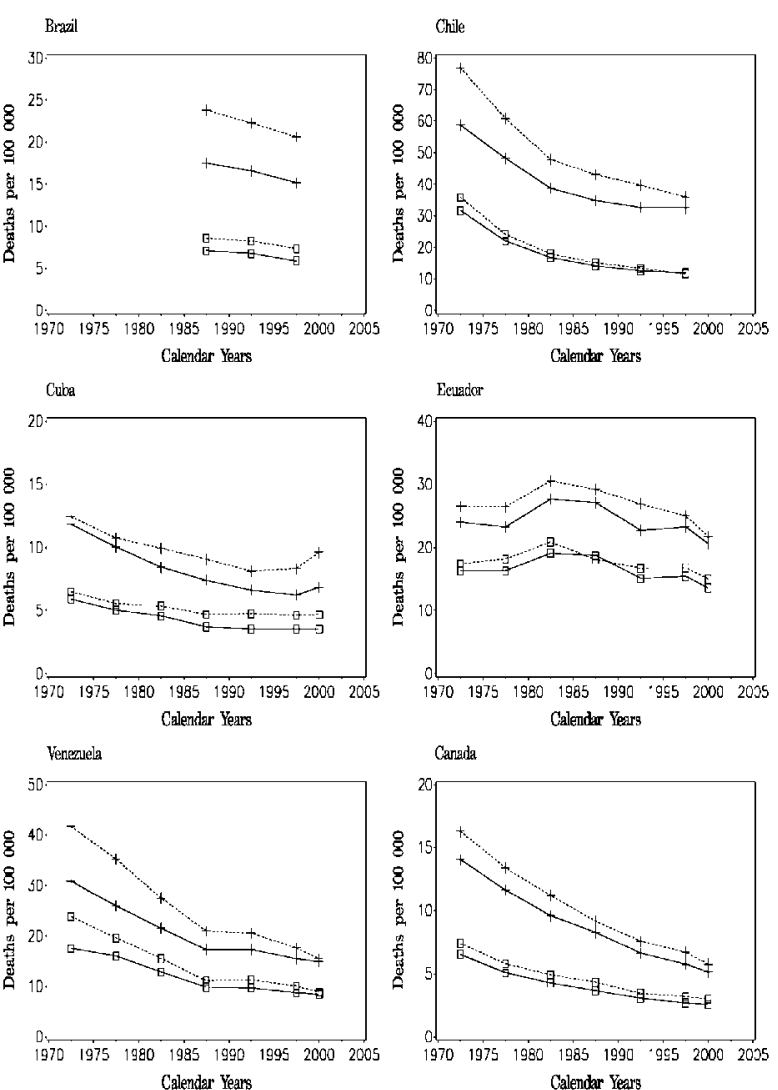

Calendar Years

Intestines
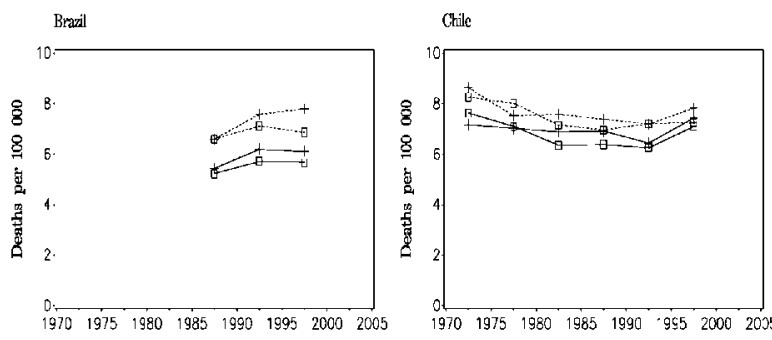

Calendar Years
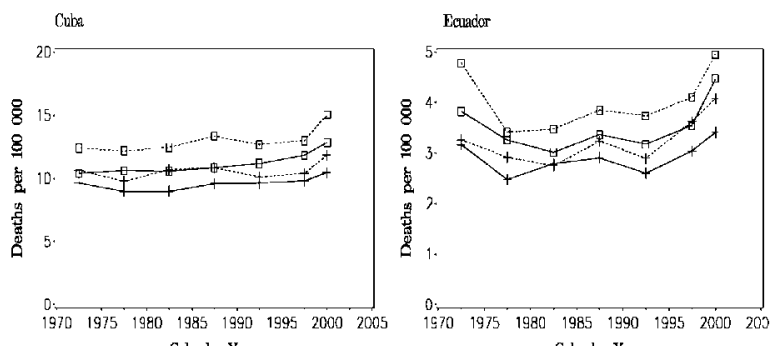

Calendar Years

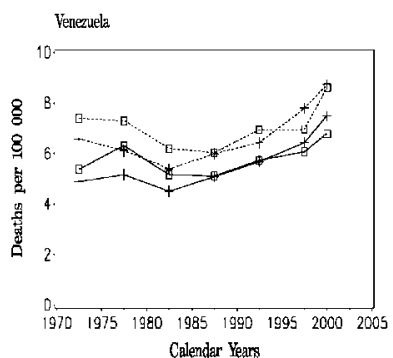

Calendar Years

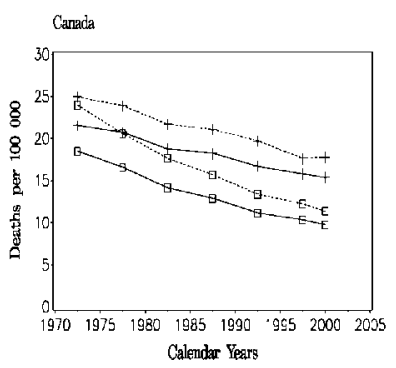

Calendar Years

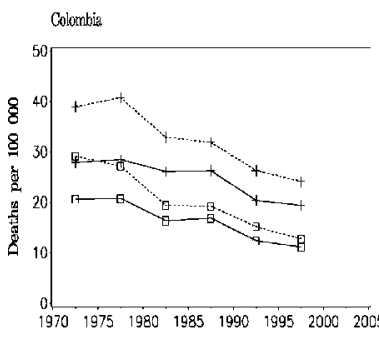

Calendar Yerors

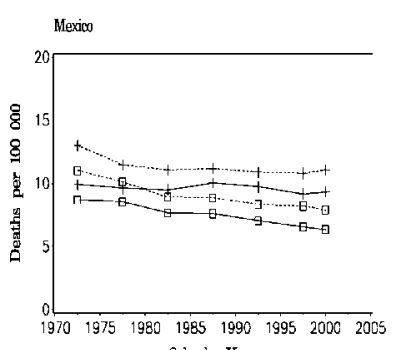

C.lendar Yeara

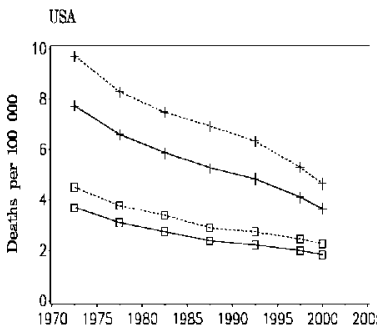

Calendar Years

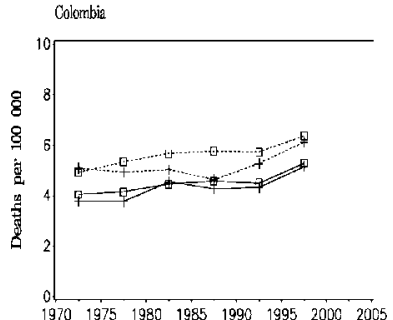

Colendar Years

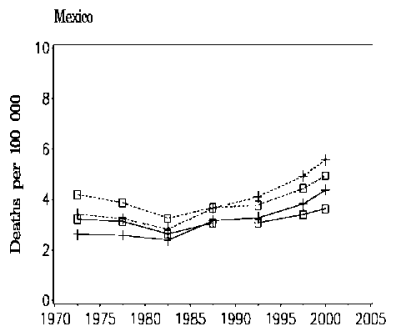

C.alendar Yearss

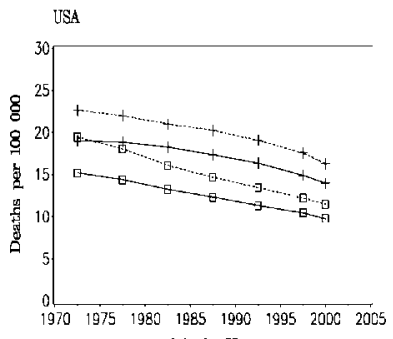

Calendar Years 
(c)
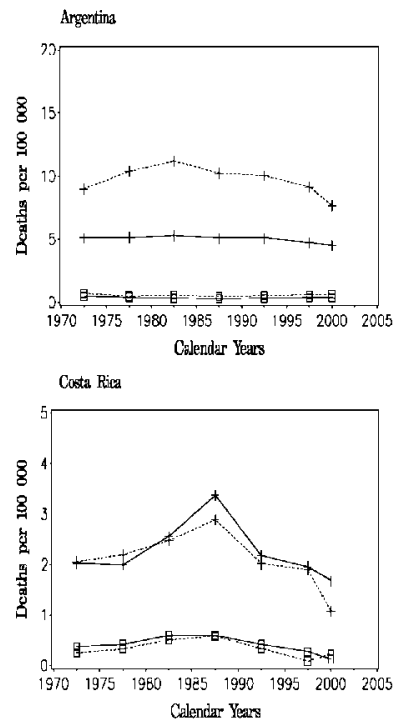

Calendar Years

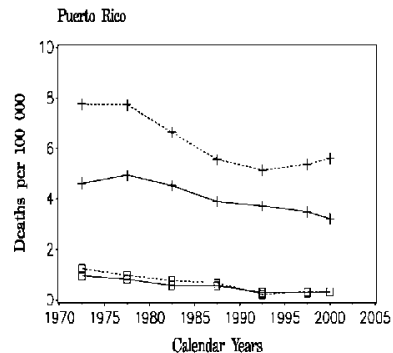

Calendar Years

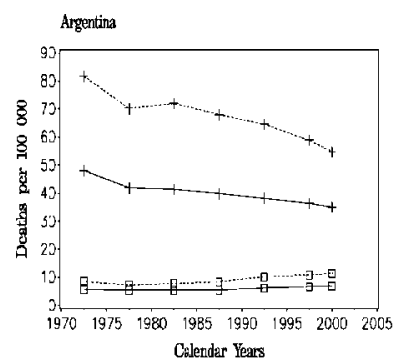
Cilendar Years

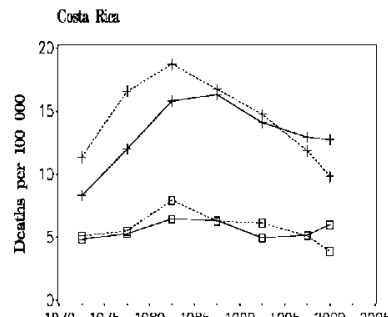
Calendar Years

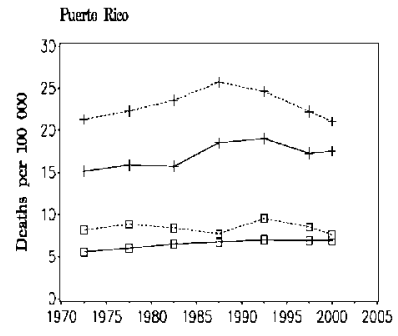

Cilendar Years

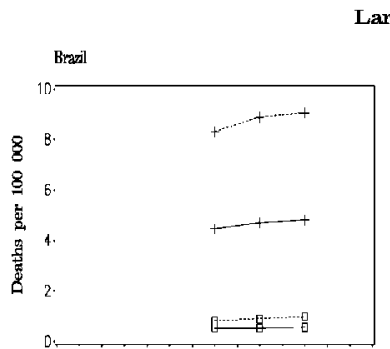

Larynx

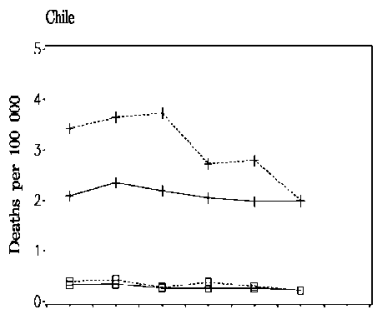

$\begin{array}{lllllllllllll}1985 & 1990 & 1995 & 2000 & 2005 & 0.7 & 1975 & 1980 & 1985 & 1990 & 1995 & 2000 & 2025\end{array}$ Calendar Years

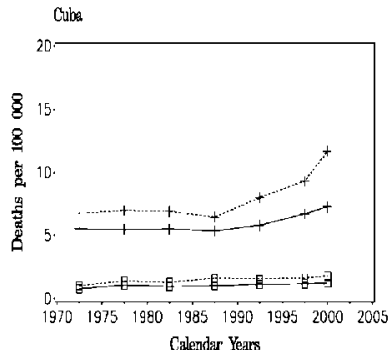

Calendar Years
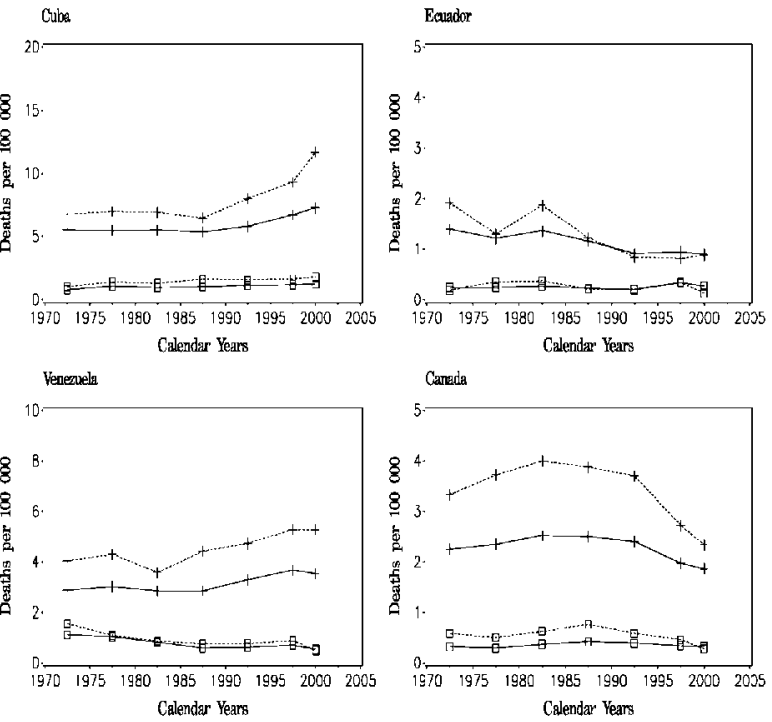

Lung
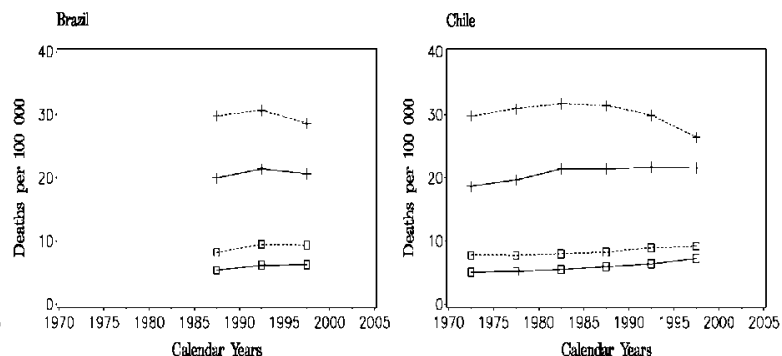

Calendar Years

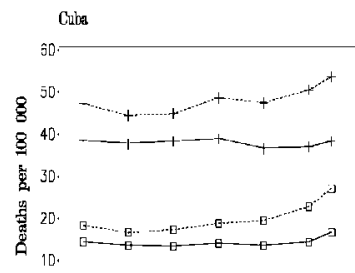

$\begin{array}{lllllllll}0.8 & 19 / 2 & 19 / 5 & 1980 & 1985 & 1990 & 1995 & 2000 & 2005\end{array}$ Calender Yéars

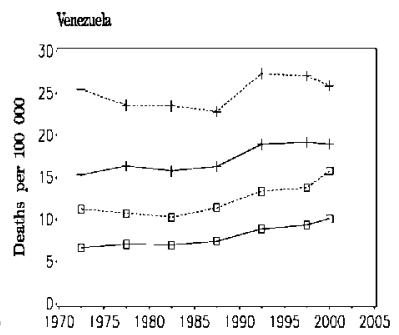

Calender Years

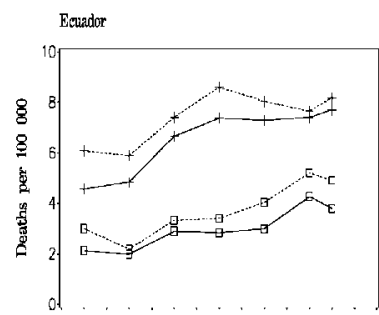

$1985^{\circ} 19900^{\circ} 955^{\circ} 2000203$ Calcmitar Years

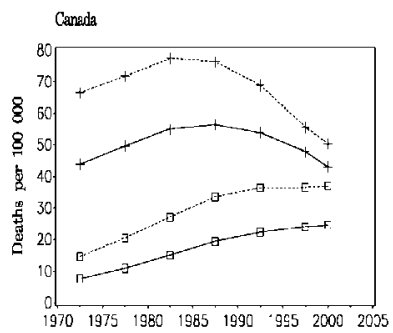

Calentar Years

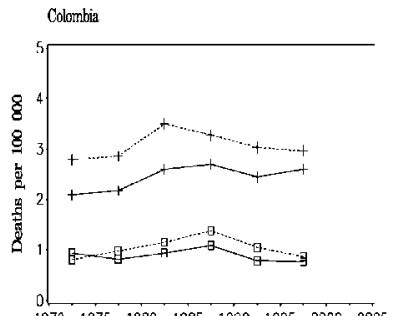

Calendar Yeatrs

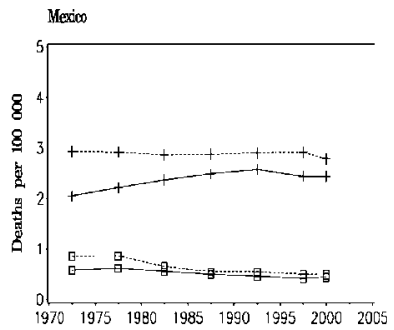

Calendar Years

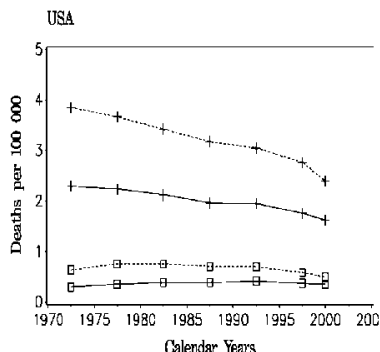

Calendar Years

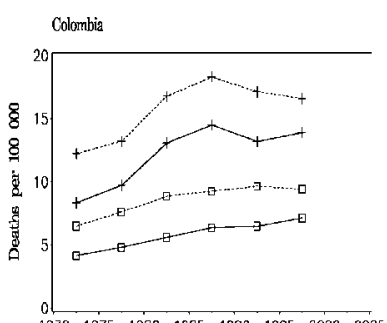
Calendar Year

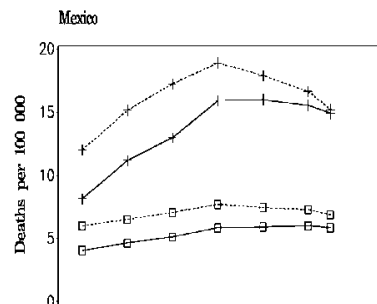

$19 / 0^{\circ} 19^{\circ} / 5^{\circ} 1980^{\circ} 19^{\circ} 1990^{\circ} 199^{\circ} 2000200^{\circ}$ Calendar Years

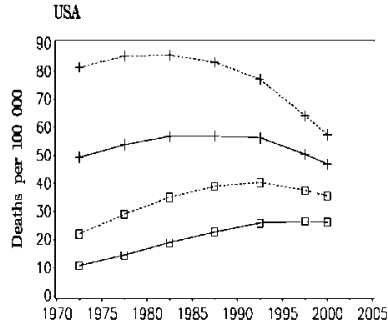

Calender Years 
(d)
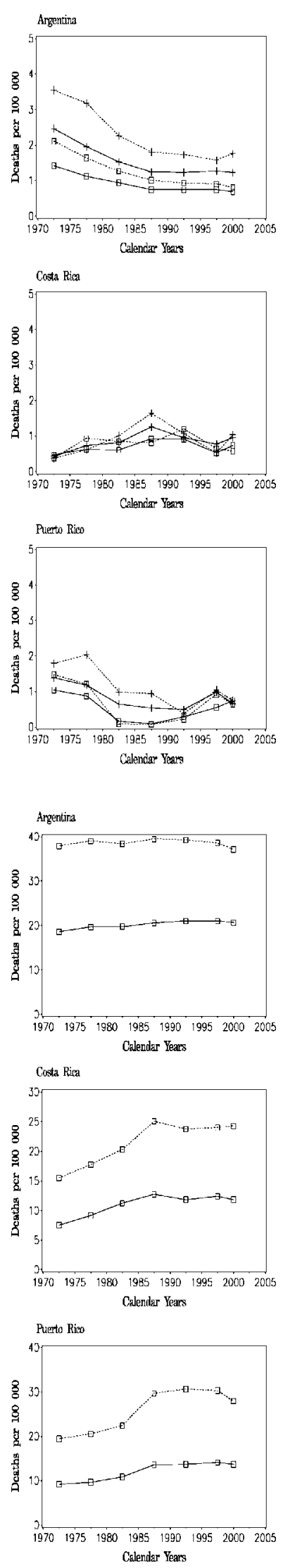

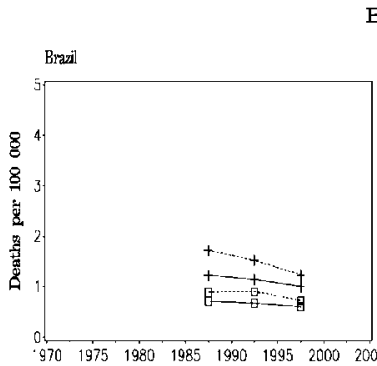

Calendar Years

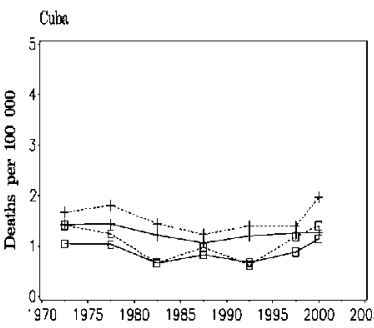

Calendar Yeers

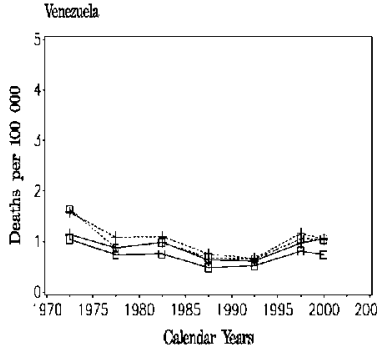

Calendar Years
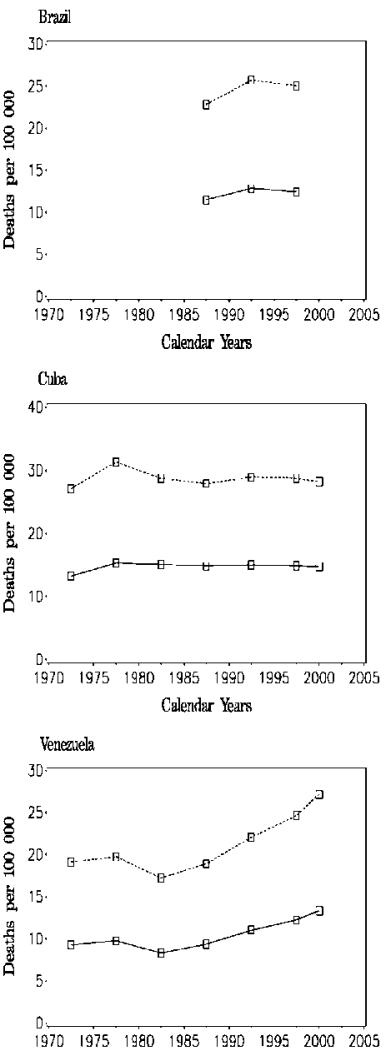

Calendar Years
Bone
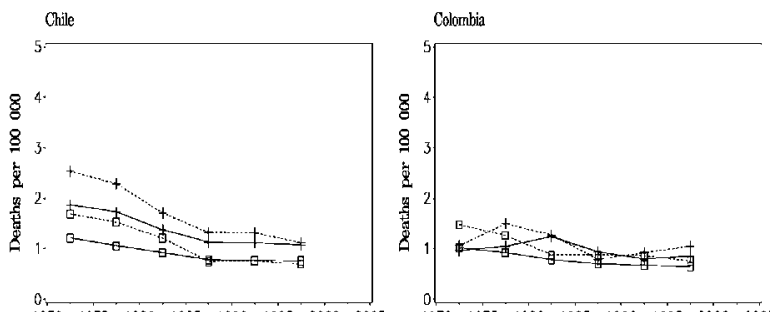

Calendar Years

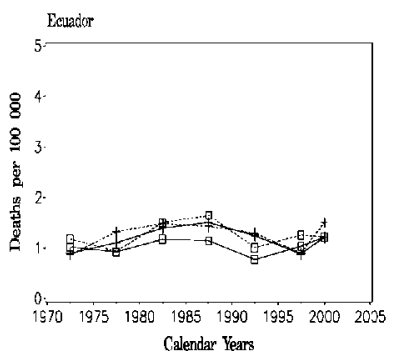

Calendar Years

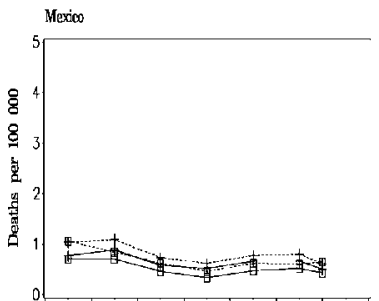

Calendar Years

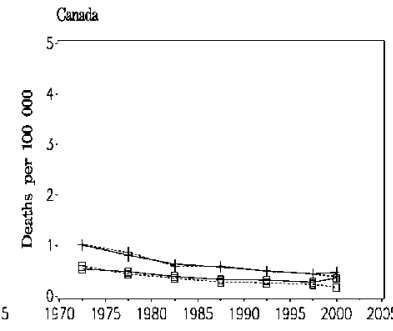

Calendar Years

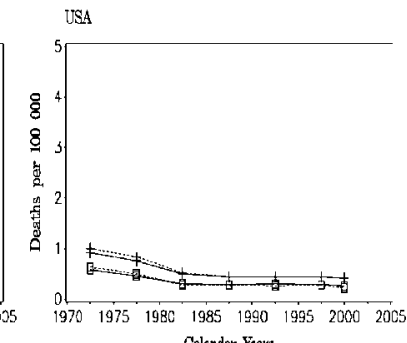

Calendar Years

Breast
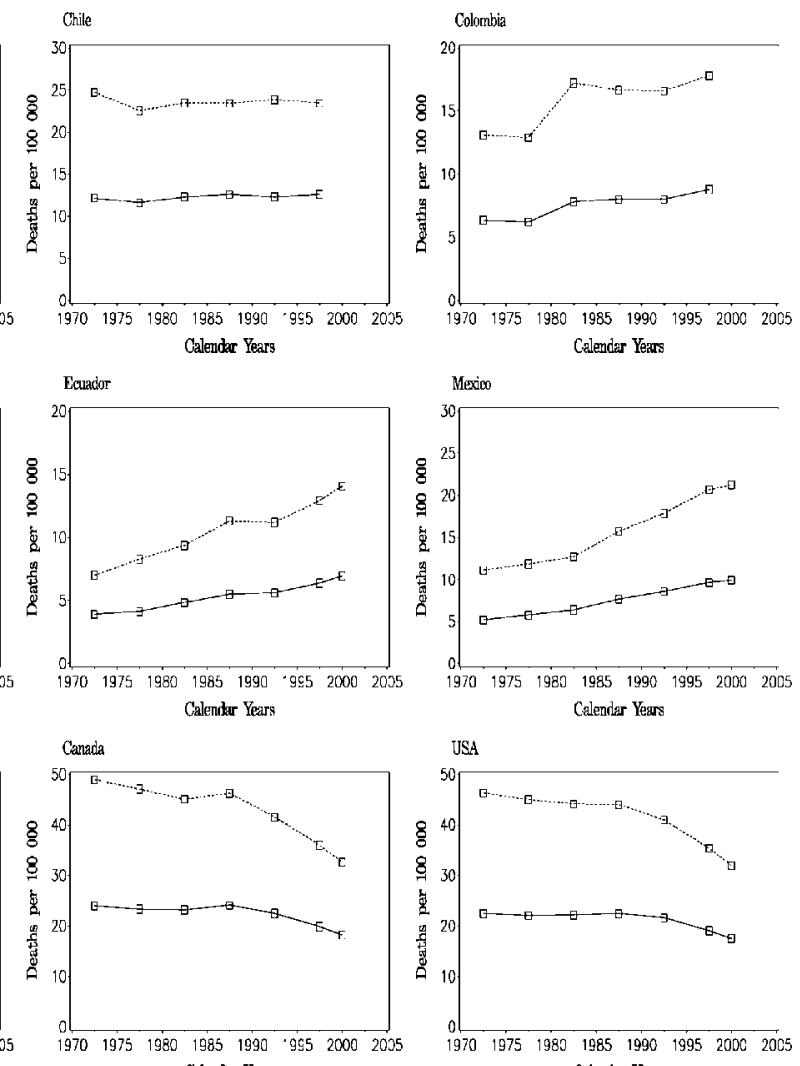

Calenilar Yoars

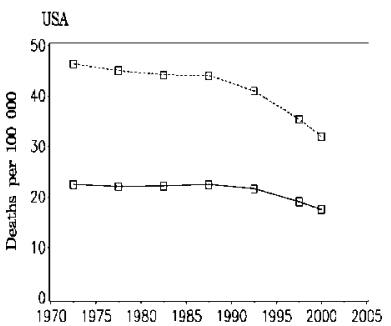

C.alendar Yegra 
(e)

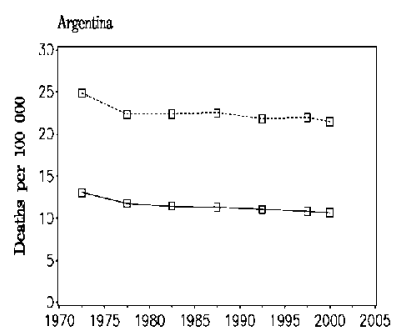
Colendar Years

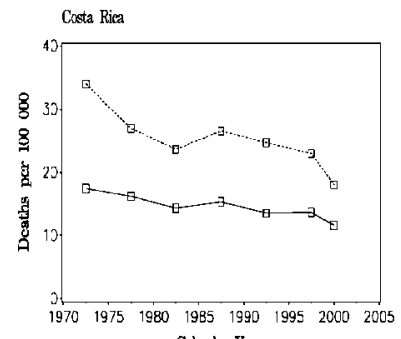

Calendar Years

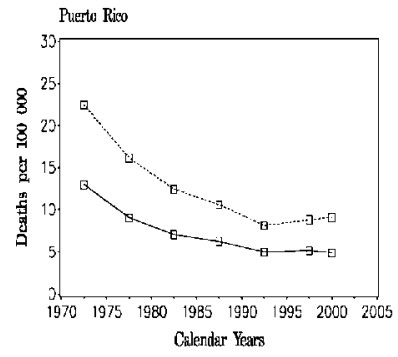

Ovary

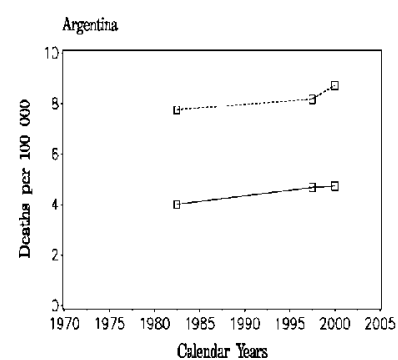
Calendar Years
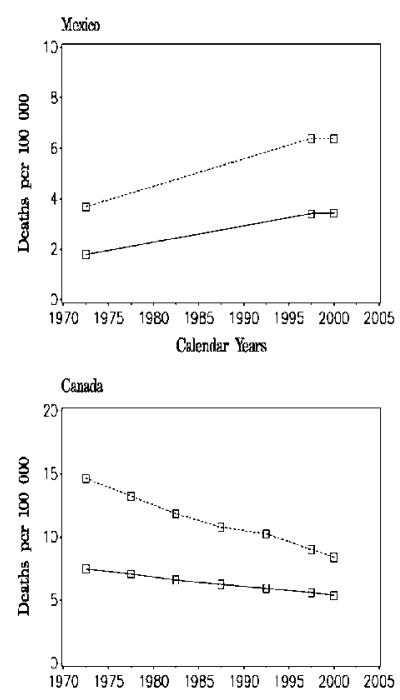

Calendar Years

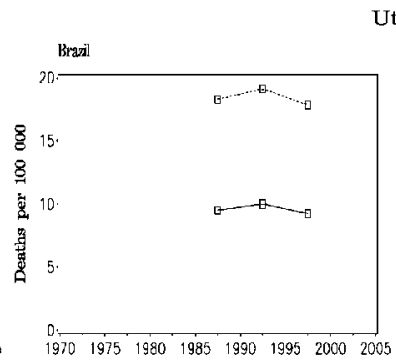

Calender Years

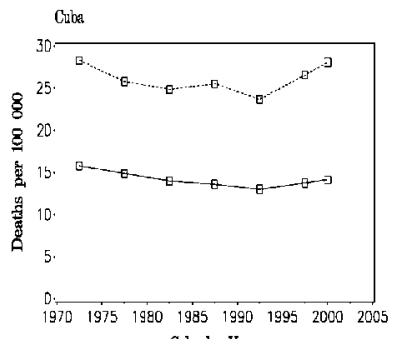

Calender Year
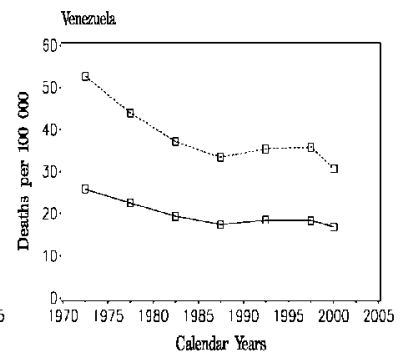

(1)

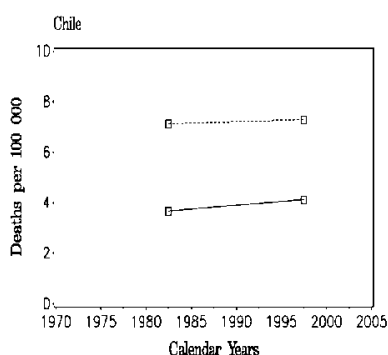
Calender Years

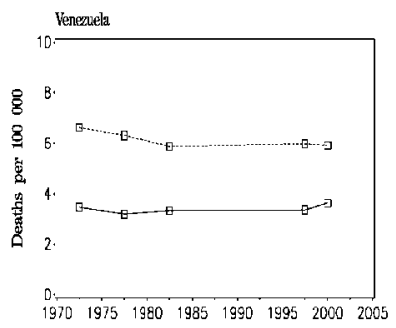

Calender Years

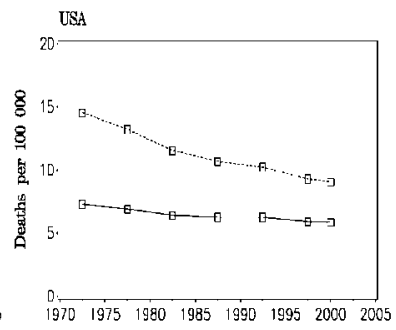

Calender Years
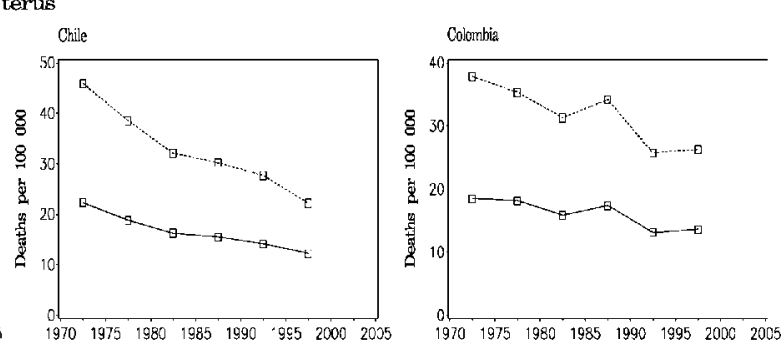

Calendar Years

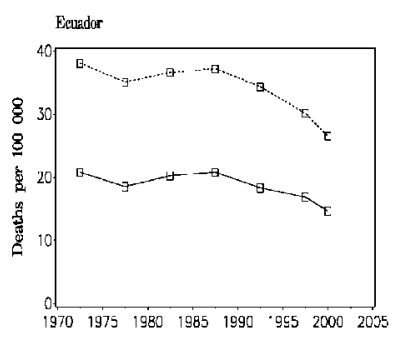

Calender Years

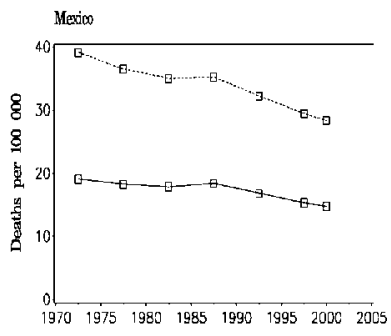

Calendar Years
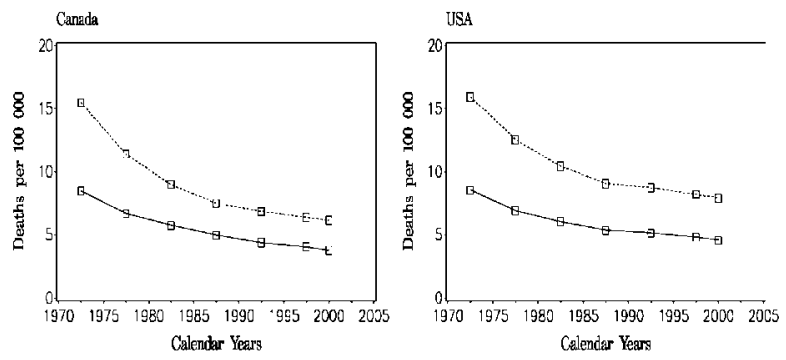

Textis

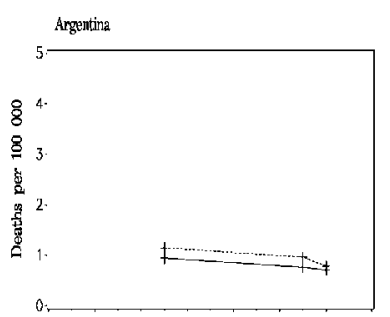

Calendax Years

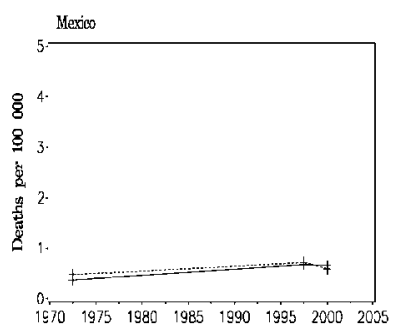

Calendar Years

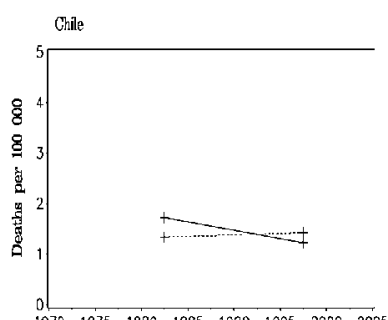
Calendar Years

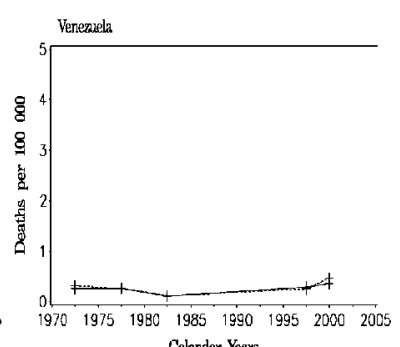
Calendar Years

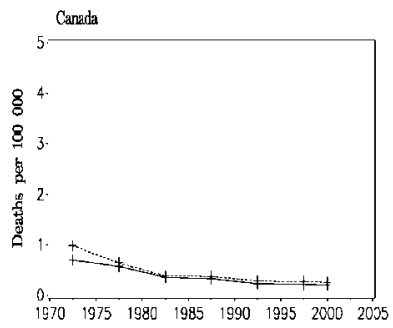

Calendar Years

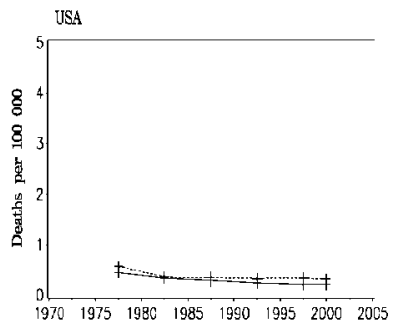

Calendar Years 
(f)

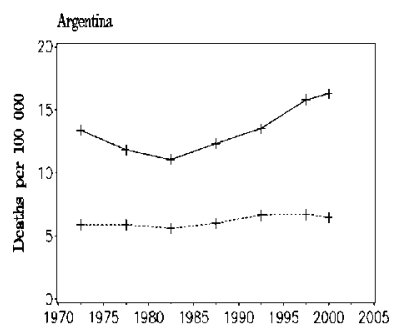

Cglendar Years

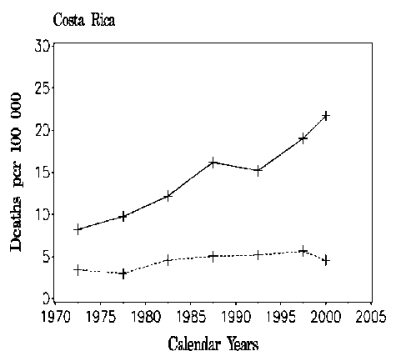

Cslendar Years

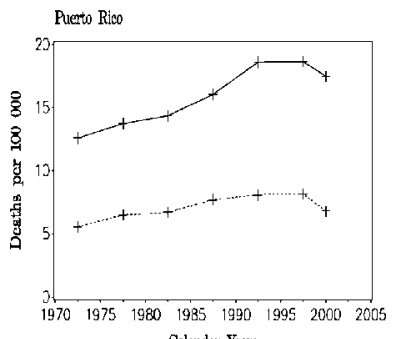

Cderdar Years
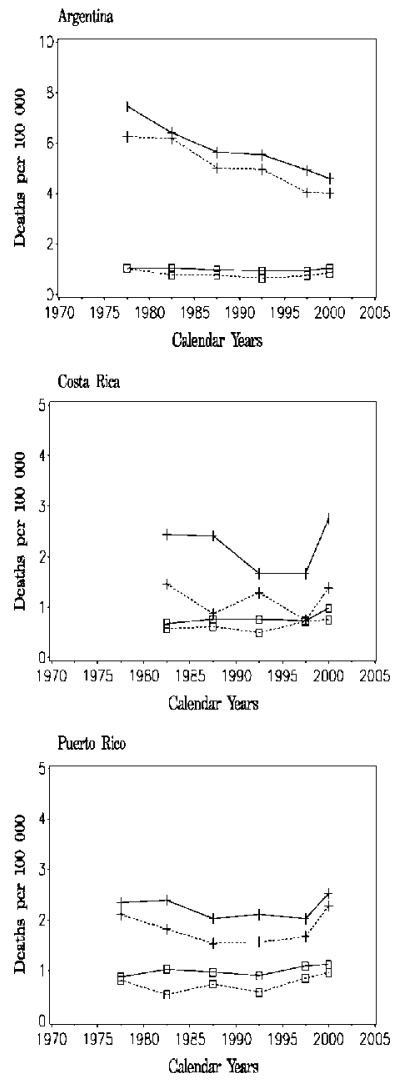

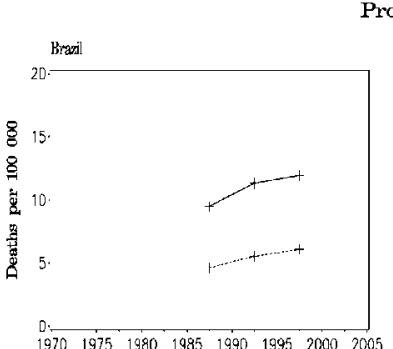

Calendar Years

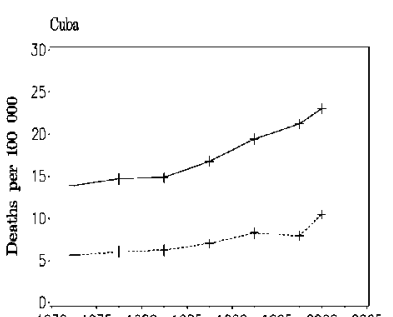

Calendar Years

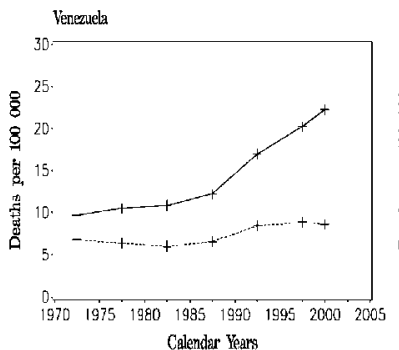

Calendar Years

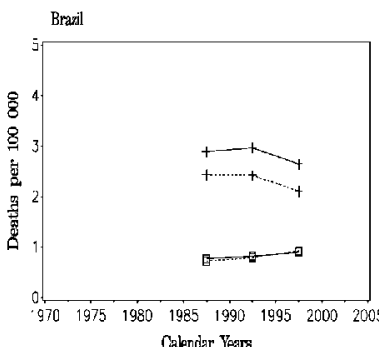

Calendar Years
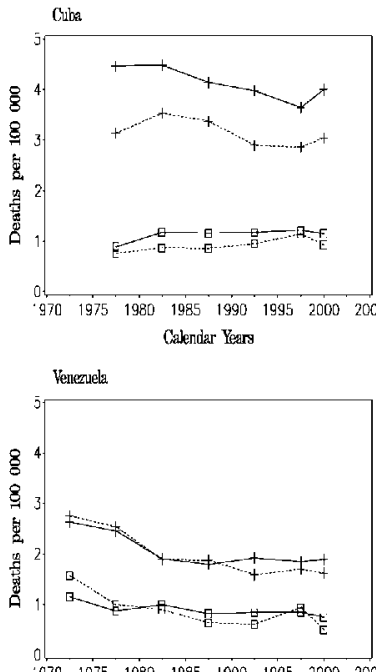

Calendar Yegers
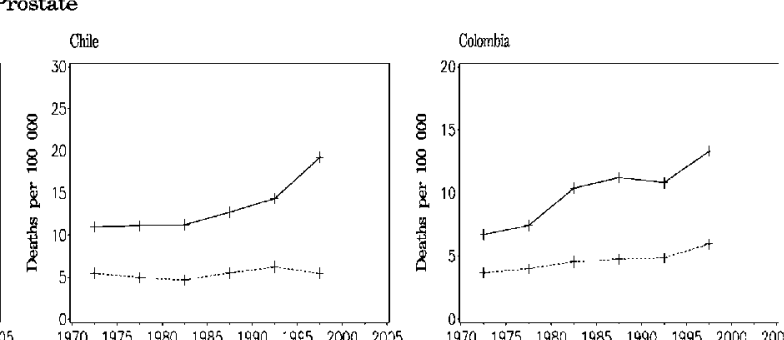

Calendar Years

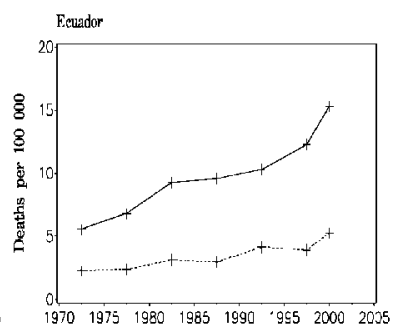

Calendar Years

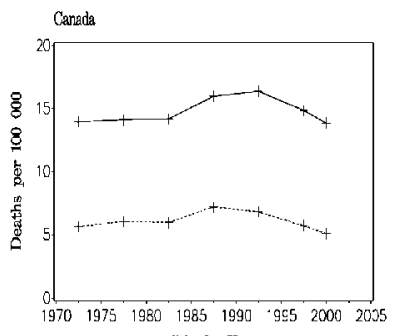

Calendar Years

Bladder
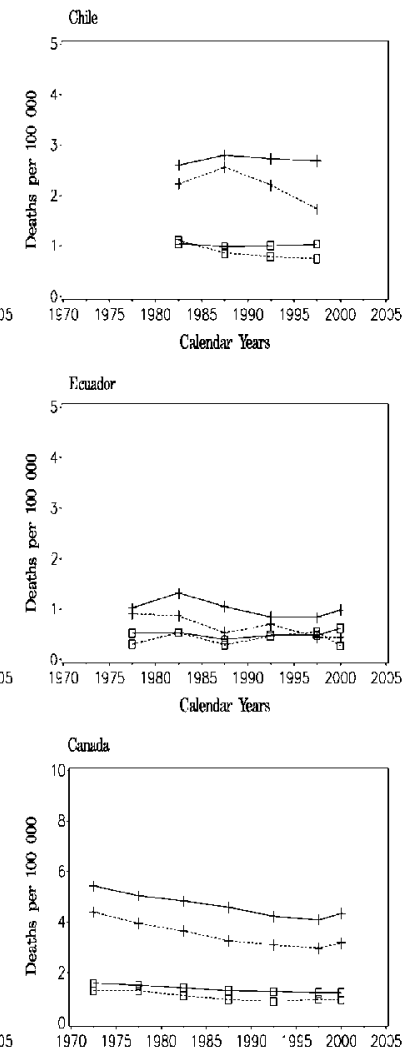

Caleniar Years

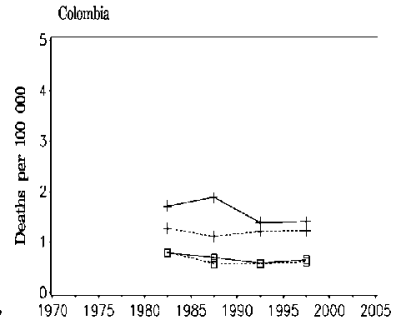

Calerdar Years

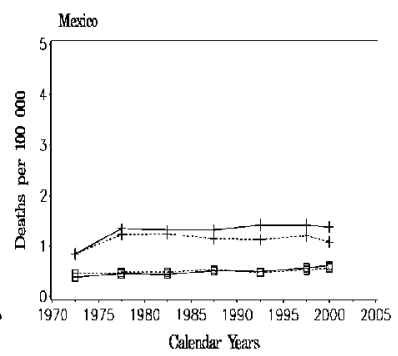

19851990
Colleader Years

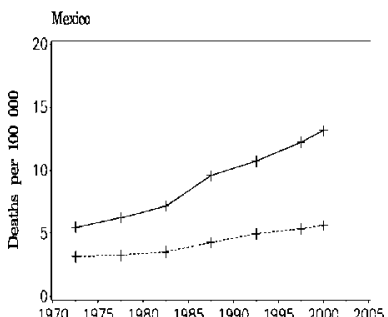

Caleandar Yearos

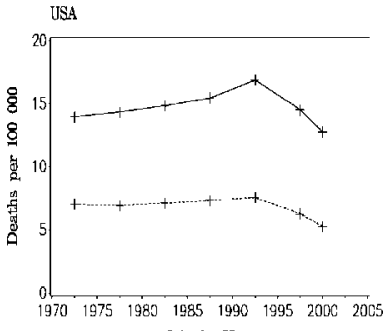

Calendar Years

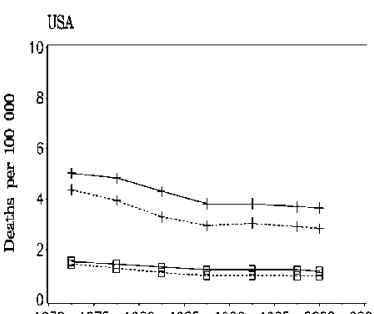

$\begin{array}{llllll}1985 & 1990 & 1995 & 2000 & 2005\end{array}$ 

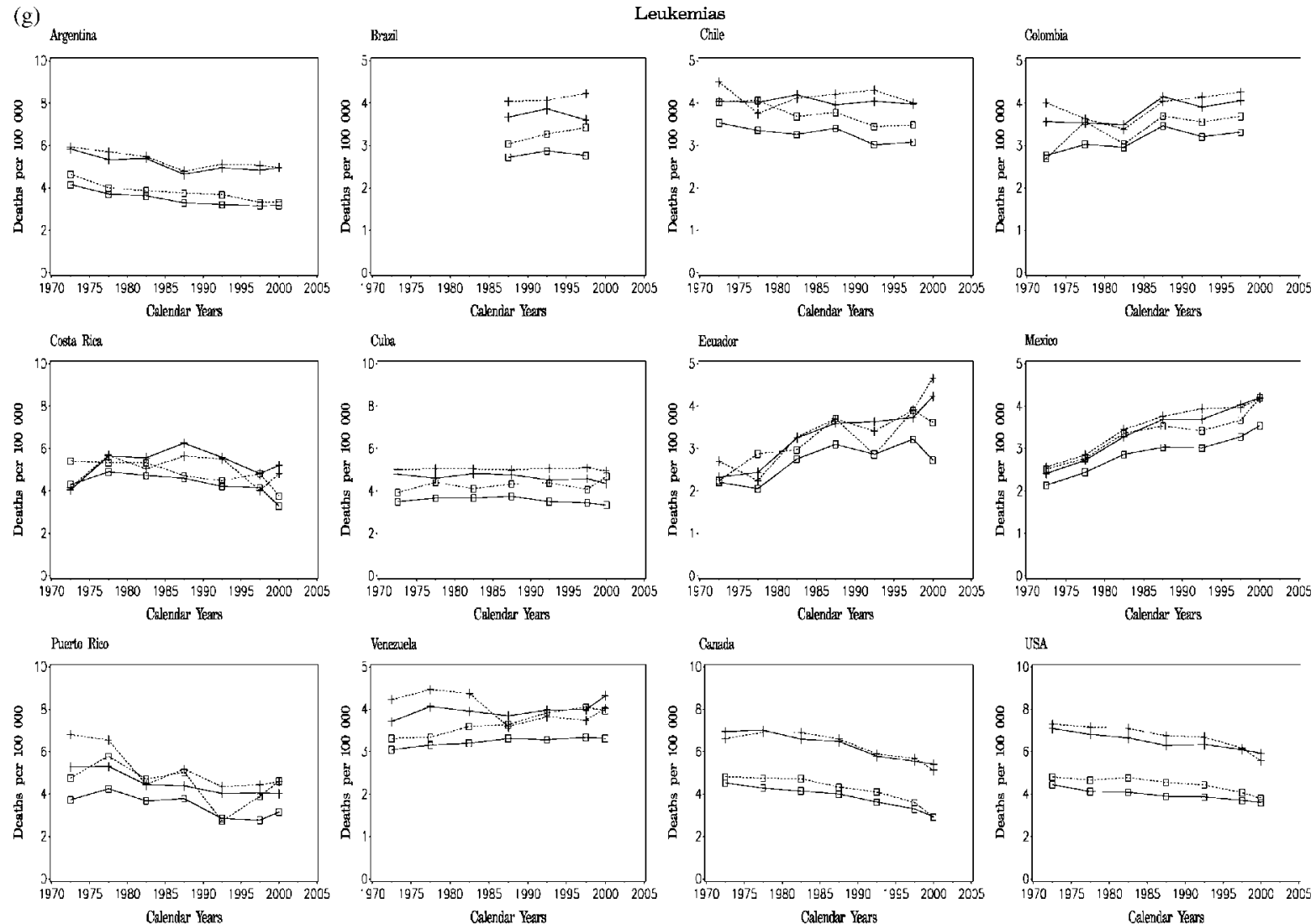

Calendar Years

Calendar Years

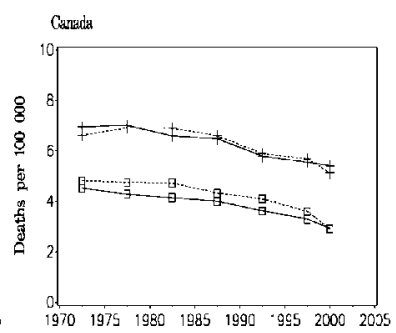

Calendar Years

Calendar Years
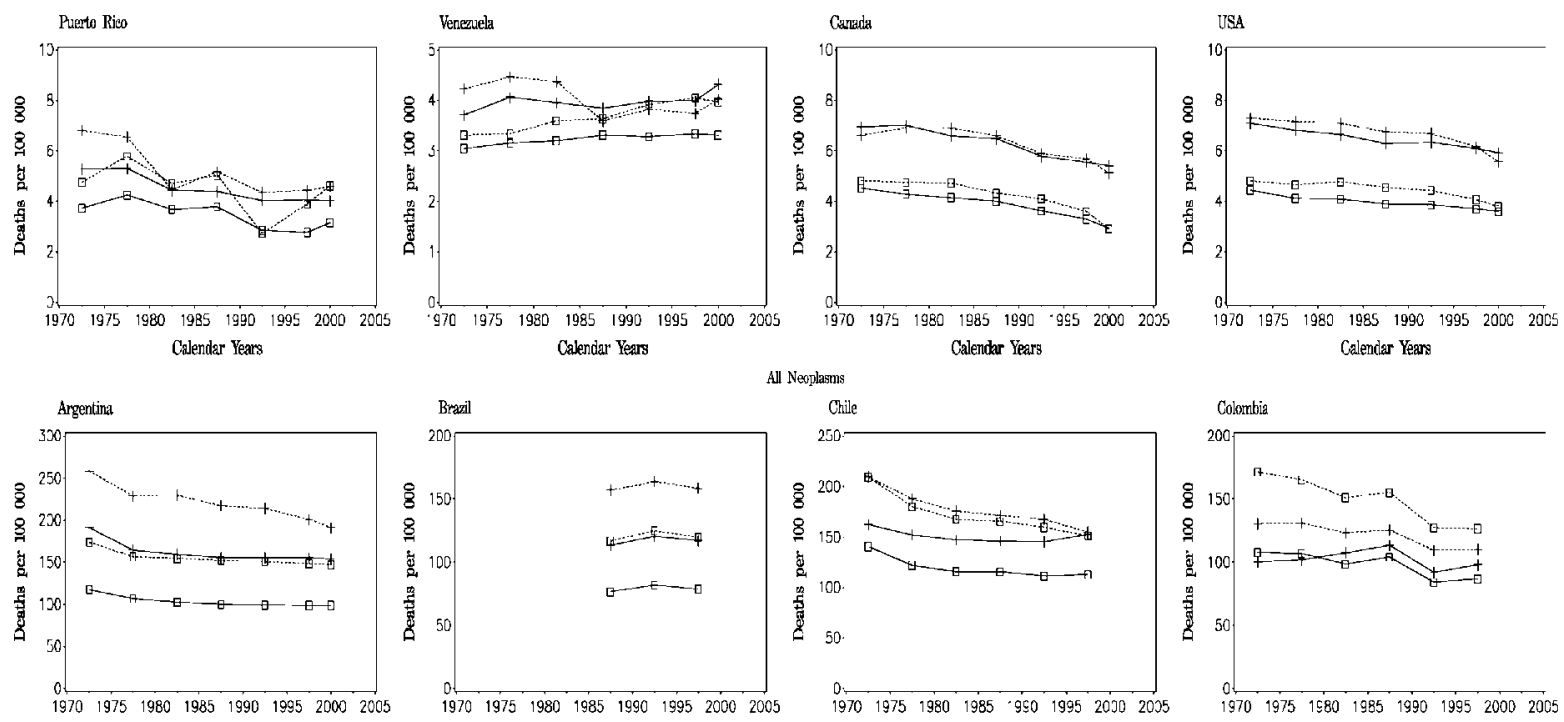

All Neoplasms

Calender Year
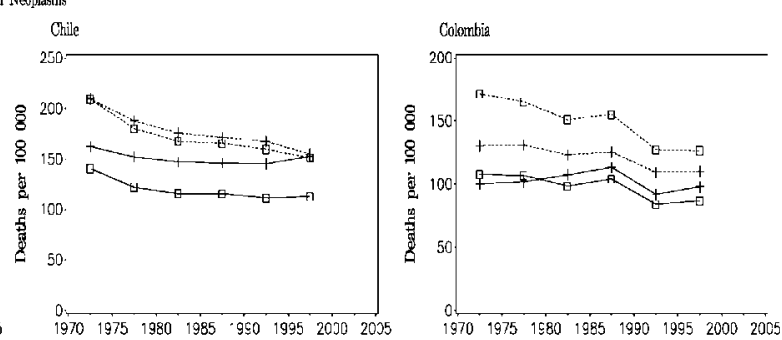

Calendar Years
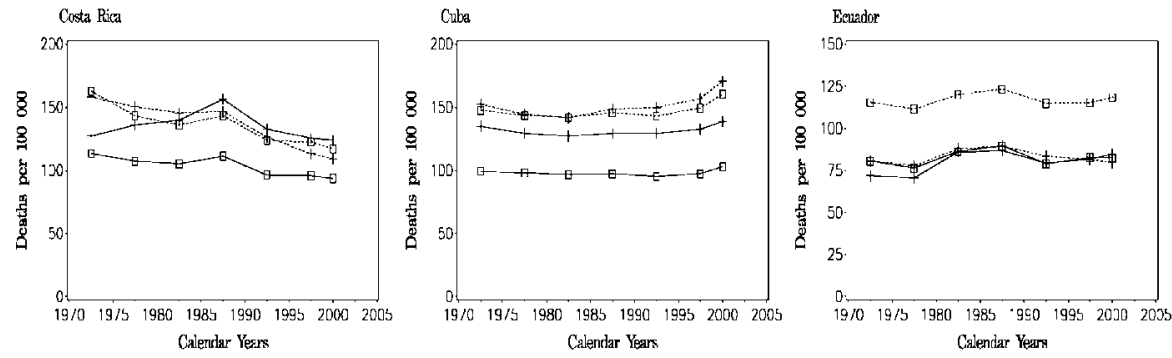

Calendar Years
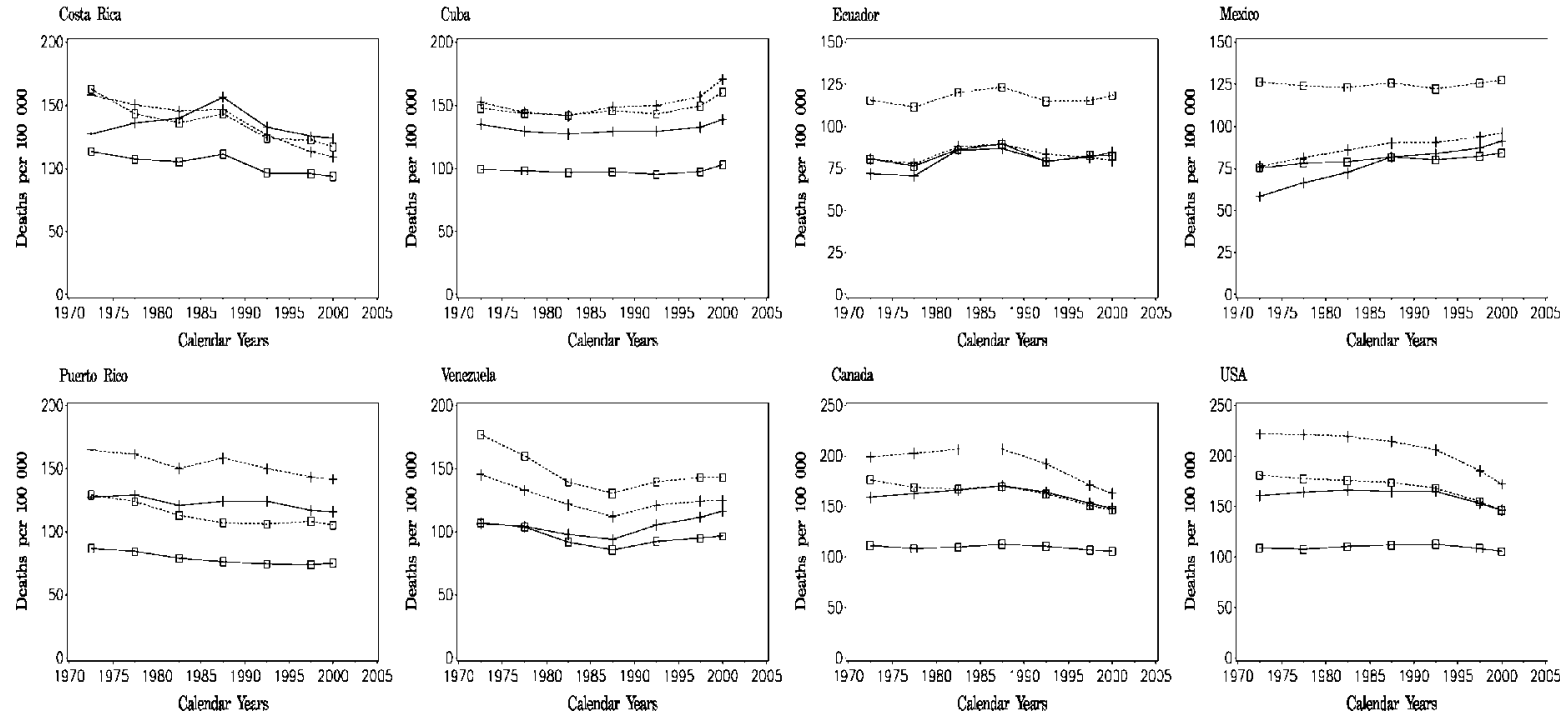

Figure 2. Trends in age-standardized (world population) death rates per 100000 from 14 cancer sites plus total cancer mortality in selected countries of the Americas, between 1970 and 2000; solid line and crosses, men, all ages; dotted line and crosses, men, truncated 35-64 years; solid line and open squares, women, all ages; dotted line and open squares, women, truncated 35-64 years. 
(endometrium), and in several countries a substantial, though variable, proportion of deaths from uterine cancers are attributed to 'uterus unspecified'. However, since endometrial cancer mortality is rare at younger ages, truncated trends at age 35-64 years are probably due mainly to cervical cancer.

Uterine cancer rates were exceedingly high in Latin America, essentially due to high rates of cervical cancer, as also indicated by the high mortality in middle-aged women. Rates were more than 15/100000 overall and more than 30/100000 at age 35-64 in Ecuador, Mexico and Venezuela, and more than 10/100000 in all women and more than 20/100000 at age 35-64 in most other countries. Only in Puerto Rico were mortality rates lower $(4.9 / 100000$ in all women, and 9.1/100000 in middle-aged ones). Rates in North America were around 4/100 000 overall and 7/100 000 truncated. A systematic and steady fall in uterine cancer mortality was observed since the 1970s in most Latin American countriesparticularly in middle-aged women-with the exception of Argentina and Cuba, where rates remained stable [61]. These downward trends are probably due to a decline in cervical cancer mortality, following some adoption, though still largely inadequate, of cervical screening in these countries [62, 63]. However, the excess mortality in most Latin America (still two- to four-fold higher than in North America) indicates the need of more adequate screening programs to limit the consequences of this avoidable cause of death [64, 65].

\section{Ovary}

Mortality data for ovarian cancer mortality were available only for a few countries from Latin America, and for a limited number of years. Ovarian cancer mortality rates in most Latin American countries were comparatively low (between 2 and $5 / 100000$ women) on an international scale (rates around 5-6/100000 in North America). However, upward trends were observed in Argentina, Chile and Mexico in the last decades.

This pattern probably reflects a number of factors, including-as for breast cancer-the declined parity of subsequent generations of Latin American women, although modifications of dietary and other lifestyle factors may also have played some role on ovarian cancer rates [66]. Conversely, in Canada and the USA, ovarian cancer rates are now declining mainly in middle-aged women, probably as a consequence of a more widespread utilization of oral contraceptive in subsequent generations of women [67].

\section{Prostate}

In 2000, Cuba and Venezuela had the highest prostate cancer mortality (rates over 20/100000 overall), followed by Chile and Costa Rica, with overall rates around 20/100 000. Rates at age 35-64 years were exceedingly high in Cuba (10.5/100000) and Venezuela (8.6/100000) [68]. The lowest mortality was observed in Brazil and Mexico, with rates comparable to those of North America, i.e. around 12-13/100 000 overall and 5-6/100 000 truncated. In the last decades, overall prostate cancer mortality showed a moderate upward trend in all countries from Latin America. Since, however, no appreciable trends have been observed below age 65 , it is likely that the overall trends are influenced by recent changes in diagnosis and certification of prostate cancer in the elderly [69]. This is particularly true for Chile, Costa Rica, Ecuador and Venezuela, showing substantial diverging trends over the last decade for all age and truncated rates. In Canada and the USA, mortality from prostate cancer has long been stable, but has been declining in the last decade below age 65 years. In the elderly, after a rise up to the 1990s, a subsequent fall in rates has been observed [70].

Prostate cancer incidence essentially reflects the variable adoption of prostate specific antigen (PSA) testing in various populations. The favorable mortality trends observed in North America, however, likely reflect an increase in survival rates, due to improvements in treatment, including an earlier adoption of trans-urethral resection of the prostate, as well as the use of hormonal and radio-therapy for patients with locally advanced prostate cancer [5, 71-73]. An earlier diagnosis of the disease, following the introduction of PSA since the late 1980s or early 1990s, may also have played a role over the last few years considered [74, 75]. In order to reduce prostate cancer mortality in Latin American countries, it is therefore important that diagnostic advancements and modern therapeutic approaches for prostate cancer are urgently adopted.

\section{Testis}

As for ovarian cancer, testicular cancer mortality data were only available for a few countries and calendar years. In 2000, rates in Latin America ranged between 0.3/100000 in Cuba and 1.3/100 000 in Chile. In North America, as in Europe [1], mortality rates have been steadily declining since the $1970 \mathrm{~s}$, and in 2000 were about $0.2 / 100000$. Testicular cancer mortality is thus now appreciably higher in Latin America than in North America, reflecting an inadequate adoption of modern platinum-based chemotherapy regimens, which have substantially reduced mortality from testicular cancer in developed areas of the world since the early 1970s [76, 77]. Again, this calls for urgent adoption of modern treatment for a largely avoidable cause of death in young men.

\section{Bladder}

In 2000, bladder cancer mortality rates in Argentina and Cuba for men were at values comparable to those of North American men (i.e. about 4/100 000). Male rates were lower in other countries of Latin America. In the last decades, rates showed a downward trend in Argentina and Venezuela, as in Canada and the USA, whereas trends were less clear in other countries. Since bladder cancer is another neoplasm strongly related to tobacco smoking [21], its mortality rates, with recent declines for males in various countries of Latin America, may reflect the patterns of tobacco smoking for subsequent generations of American men. Moreover, a variable role in the fall in bladder cancer mortality has probably been 
played by reduced occupational exposure to carcinogens, too [78]. Higher bladder cancer mortality rates in Argentina and Cuba may also be related to black tobacco smoking [79, 80]. Bladder cancer in women is rarer, and its rates show no clear pattern of trends over time. As for lung cancer, the highest rates (around 1/100000) were observed in Cuba, where tobacco smoking has long been common also in women.

\section{Leukemias}

In 2000, mortality from leukemias in men was between 3 and 5/100000 in countries from Latin America, i.e. slightly lower than that of Canada and the USA (rates around 5-6/100000). Values in women from Latin America were between 2 and 4/100 000, comparable with those of North America. In North America, a steady decrease was observed since the early 1970 s, following the adoption of integrated therapy regimens, mainly in children and young adults [81-83]. Trends in countries of Latin America were less consistent, with some declines in Argentina, and even increases in Ecuador and Mexico. As for testicular cancer, this would suggest some delay in the adoption of modern effective therapy schemes, although it is possible that these trends were also influenced by improved accuracy of diagnosis and certification [84].

\section{All neoplasms (benign and malignant)}

Total cancer mortality in countries of Latin America showed different patterns, which reflect the variable mortality rates and trends for site-specific cancers. In 2000, the highest total male cancer mortality was observed in Argentina and Chile, with rates comparable with those of Canada and the USA, i.e. about 150/100 000. For women, Chile and Cuba had the highest rates in Latin America (113.7 and 102.9/100 000, respectively), again comparable with those of North America (around 105/100 000). These rates reflect the comparatively high mortality from cancer of the stomach (for Chile), lung and intestine (for Argentina) in men, and of stomach and uterus (for Chile), intestines and lung (for Cuba) in women. Colombia, Ecuador and Mexico [85] had the lowest male cancer mortality, due to low mortality from stomach, colorectal and lung cancer in those countries. For women, the lowest rates were in Brazil and Puerto Rico, reflecting their low stomach and cervical cancer rates. In Argentina, Chile, Colombia, Costa Rica and Venezuela cancer mortality rates tended to decline, particularly in men. Rates were stable in Ecuador and Puerto Rico, and increasing in Mexico and Cuba.

Thus, mortality from some common cancers (including colorectal and lung) is still low in Latin America compared with Canada and the USA, and decreasing trends have been observed in the last decades for some cancer sites (including stomach, uterus, lung and other tobacco-related cancers) in several countries. However, mortality from female lung and breast cancers has been increasing in most countries of Latin America, and several countries still showed an extremely elevated mortality from cancer of the cervix.

Favorable trends in cancer mortality in Latin America in the near future would therefore require an integrated strategy of prevention focused on the control of tobacco and alcohol, particularly for countries like Cuba and Brazil, adoption of a richer and more favorable diet for stomach cancer particularly in Chile, Costa Rica and Colombia, as well as screening and early diagnosis for cervical cancer. Adoption of therapeutic advancements for selected neoplasms amenable to treatment, including testicular cancer and leukemias, is also a priority for most countries of Latin America [86].

\section{Acknowledgements}

We thank M.P. Bonifacino for editorial assistance. This work was conducted with the contribution of the Italian Association for Cancer Research, and the Italian and Swiss Leagues Against Cancer.

\section{References}

1. Levi F, Lucchini F, Negri E et al. Cancer mortality in Europe, 19951999, and an overview of trends since 1960. Int J Cancer 2004; 110 : $155-169$.

2. Levi F, Lucchini F, Negri E, La Vecchia C. Worldwide patterns of cancer mortality, 1990-1994. Eur J Cancer Prev 1999; 8: 381-400.

3. Parkin DM, Bray F, Ferlay J, Pisani P. Estimating the world cancer burden: GLOBOCAN 2000. Int J Cancer 2001; 94: 153-156.

4. Wingo PA, Cardinez CJ, Landis $\mathrm{SH}$ et al. Long-term trends in cancer mortality in the United States, 1930-1998. Cancer 2003; 97: 3133-3275.

5. Jemal A, Clegg LX, Ward E et al. Annual report to the nation on the status of cancer, 1975-2001, with a special feature regarding survival. Cancer 2004; 101: 3-27.

6. La Vecchia C, Lucchini F, Negri E et al. Trends in cancer mortality in the Americas, 1955-1989. Eur J Cancer 1993; 29A: $431-470$.

7. La Vecchia C, Negri E, Levi F et al. Cancer mortality in Europe: effects of age, cohort of birth and period of death. Eur $\mathrm{J}$ Cancer 1998; 34: 118-141.

8. World Health Organization Statistical Information System. WHO mortality database. Available from: http://www3.who.int/whosis/ menu.cfm. Geneva: World Health Organization 2003.

9. World Health Organization. International Classification of Disease: 8th Revision. Geneva: World Health Organization 1967.

10. World Health Organization. International Classification of Disease: 9th Revision. Geneva: World Health Organization 1977.

11. World Health Organization. International Statistical Classification of Disease and Related Health Problems: 10th Revision. Geneva: World Health Organization 1992.

12. Pan American Health Organization (PAHO). Special Program for Health, Technical Information System. Regional Mortality Database, 2001. Available from: http://www.paho.org.

13. Doll R, Smith PG. Comparison between registries: age-standardized rates. In Waterhouse JAH, Muir CS, Shanmugaratnam K et al. (eds): Cancer Incidence in Five Continents, Vol IV. IARC Sci Publ No 42. Lyon: International Agency for Research on Cancer 1982; 671-675.

14. Percy C, Staneck E, Gloeckler L. Accuracy of cancer death certification and its effects on mortality statistics. Am J Public Health 1981; 71: 242-250.

15. Doll R, Peto R. The causes of cancer: quantitative estimates of avoidable risk of cancer in the United States today. J Natl Cancer Inst 1981; 66: 1191-1308. 
16. Boyle P. Relative value of incidence and mortality data in cancer research. Recent results. Cancer Res 1989; 114: 41-63.

17. Fernandez Garrote L, Sankaranarayanan R, Lence Anta JJ et al. An evaluation of the oral cancer control program in Cuba. Epidemiology 1995; 6: 428-431.

18. International Agency for Research on Cancer. IARC Monographs on the Evaluation of Carcinogenic Risk to Humans, Vol. 44: Alcohol Drinking. Lyon: International Agency for Research on Cancer 1988.

19. Franceschi S, Talamini R, Barra $S$ et al. Smoking and drinking in relation to cancers of the oral cavity, pharynx, larynx and esophagus in Northern Italy. Cancer Res 1990; 50: 6502-6507.

20. Wunsch-Filho V, de Camargo EA. The burden of mouth cancer in Latin America and the Caribbean: epidemiologic issues. Semin Oncol 2001; 28: $158-168$.

21. International Agency for Research on Cancer. IARC Monographs on the Evaluation of Carcinogenic Risk to Humans, Vol. 83: Tobacco Smoke and Involuntary Smoking. Lyon: International Agency for Research on Cancer 2004.

22. World Health Organization. Tobacco or Health. A Global Status Report. Geneva: World Health Organization 1997.

23. World Cancer Research Fund. Food, Nutrition, and the Prevention of Cancer: a Global Perspective. Washington, DC: American Institute for Cancer Research 1997.

24. Franco EL, Kowalski LP, Oliveira BV et al. Risk factors for oral cancer in Brazil: a case-control study. Int J Cancer 1989; 43: 992-1000.

25. Castellsague X, Muñoz N, de Stefani E et al. Influence of mate drinking, hot beverages and diet on esophageal cancer risk in South America. Int J Cancer 2000; 88: 658-664.

26. Blot WJ, Devesa SS, Kneller RW, Fraumeni JF. Rising incidence of adenocarcinoma of the esophagus and gastric cardia. JAMA 1991; 265: $1287-1289$.

27. La Vecchia C, Negri E, Lagiou P, Trichopoulos D. Oesophageal adenocarcinoma: a paradigm of mechanical carcinogenesis? Int J Cancer 2002; 102: 269-270.

28. Vaughan TL, Davis S, Kristal A, Thomas DB. Obesity, alcohol, and tobacco as risk factors for cancers of the esophagus and gastric cardia: adenocarcinoma versus squamous cell carcinoma. Cancer Epidemiol Biomarkers Prev 1995; 4: 85-92.

29. La Vecchia C, Negri E, D’Avanzo B, Franceschi S. Electric refrigeration use and gastric cancer risk. Br J Cancer 1990; 62: 136-137.

30. La Vecchia C, Munoz SE, Braga $\mathrm{C}$ et al. Diet diversity and gastric cancer. Int J Cancer 1997; 72: 255-257.

31. Muñoz N. Is Helicobacter pylori a cause of gastric cancer? An appraisal of the seroepidemiologic evidence. Cancer Epidemiol Biomarkers Prev 1994; 3: 445-451.

32. Muñoz N, Kato I, Peraza S et al. Prevalence of precancerous lesions of the stomach in Venezuela. Cancer Epidemiol Biomarkers Prev 1996; 5: 41-46.

33. Morris Brown L. Helicobacter pylori: epidemiology and routes of transmission. Epidemiol Rev 2000; 22: 283-297.

34. Trédaniel J, Boffetta P, Buiatti E et al. Tobacco smoking and gastric cancer: a review and meta-analysis. Int J Cancer 1997; 72: 565-573.

35. Ries LA, Wingo PA, Miller DS et al. The annual report to the nation on the status of cancer, 1973-1997, with a special section on colorectal cancer. Cancer 2000; 88: 2398-2424.

36. Muñoz SE, Chatenoud L, La Vecchia $C$ et al. Trends in cancer mortality in Argentina, 1966-1991. Eur J Cancer Prev 1998; 7: 37-44.

37. Filozof C, Gonzalez C, Sereday M et al. Obesity prevalence and trends in Latin-American countries. Obes Rev 2001; 2: 99-106.

38. Aguilar-Salinas CA, Vazquez-Chavez C, Gamboa-Marrufo R et al. Obesity, diabetes, hypertension, and tobacco consumption in an urban adult Mexican population. Arch Med Res 2001; 32: 446-453.
39. Kain J, Vio F, Albala C. Obesity trends and determinant factors in Latin America. Cad Saude Publica 2003; 19: S77-S86.

40. Fernandez E, Bosetti C, La Vecchia C et al. Sex differences in colorectal cancer mortality in Europe, 1955-1996. Eur J Cancer Prev 2000; 9: 99-104.

41. Levi F, La Vecchia C, Lucchini F, Negri E. Trends in cancer mortality sex ratios in Europe, 1950-1989. World Health Stat Q 1992; 45: $117-164$.

42. Schottenfeld D, Winawer SJ. Cancers of the large intestine. In Schottenfeld D and Fraumeni JF (eds), Cancer Epidemiology and Prevention. New York: Oxford University Press 1996; 619-636.

43. La Vecchia C, Bidoli E, Barra S et al. Type of cigarettes and cancers of the upper digestive and respiratory tract. Cancer Causes Control 1990; 1: 69-74.

44. La Vecchia C, Bosetti C, Negri E et al. Cigar smoking and cancers of the upper digestive tract. J Natl Cancer Inst 1998; 90: 1670.

45. Sancho-Garnier H, Theobald S. Black (air-cured) and blond (fluecured) tobacco and cancer risk II: pharynx and larynx cancer. Eur J Cancer 1993; 29: 273-276.

46. Gallus S, Altieri A, Bosetti C et al. Cigarette tar yield and risk of upper digestive tract cancers: case-control studies from Italy and Switzerland. Ann Oncol 2003; 14: 209-213.

47. Boffetta P, La Vecchia C, Levi F, Lucchini F. Mortality patterns and trends for lung cancer and other tobacco-related cancers in the Americas, 1955-1989. Int J Epidemiol 1993; 22: 377-384.

48. Wingo PA, Ries LAG, Giovino GA et al. Annual Report to the Nation on the status of cancer, 1973-1996, with a special section on lung cancer and tobacco smoking. J Natl Cancer Inst 1999; 91: 675-690.

49. Jemal A, Chu KC, Tarone RE. Recent trends in lung cancer mortality in the United States. J Natl Cancer Inst 2001; 93: 277-283.

50. Howe HL, Wingo PA, Thun MJ et al. Annual report to the nation on the status of cancer (1973 through 1998), featuring cancers with recent increasing trends. J Natl Cancer Inst 2001; 93: 824-842.

51. Center for Disease Control and Prevention. Women and smoking: a report of the Surgeon General (Executive Summary). MMWR 2002; 51: 1-13. (No. RR-12).

52. Blot WJ, Fraumeni JF Jr. Cancer of the lung and pleura. In Schottenfeld D, Fraumeni JF Jr (eds): Cancer Epidemiology and Prevention, 2nd edition. New York: Oxford University Press 1996; 637-665.

53. Weir HK, Thun MJ, Hankey BF et al. Annual report to the nation on the status of cancer, 1975-2000, featuring the uses of surveillance data for cancer prevention and control. J Natl Cancer Inst 2003; 95: 1276-1299. [Erratum in: J Natl Cancer Inst 2003; 95: 1641].

54. Ghafoor A, Jemal A, Ward E et al. Trends in breast cancer by race and ethnicity. CA Cancer J Clin 2003; 53: 342-355.

55. Henderson BE, Pike MC, Berstein L, Ross RK. Breast cancer. In Schottenfeld D, Fraumeni JF Jr (eds): Cancer Epidemiology and Prevention, 2nd edition. New York: Oxford University Press 1996; 1022-1039.

56. Mezzetti M, La Vecchia C, Decarli A et al. Population attributable risk for breast cancer: diet, nutrition, and physical exercise. J Natl Cancer Inst 1998; 90: 389-394.

57. Early Breast Cancer Trialists' Collaborative Group. Tamoxifen for early breast cancer: an overview of the randomised trials. Lancet 1998; 351: 1451-1467.

58. Early Breast Cancer Trialists' Collaborative Group. Polychemotherapy for early breast cancer: an overview of the randomised trials. Lancet 1998; 352: 930-942.

59. Mariotto A, Feuer EJ, Harlan LC et al. Trends in use of adjuvant multi-agent chemotherapy and tamoxifen for breast cancer in the United States: 1975-1999. J Natl Cancer Inst 2002; 94: 1626-1634. 
60. Jatoi I, Miller AB. Why is breast cancer mortality declining? Lancet Oncol 2003; 4: 251-254.

61. Bocciolone L, La Vecchia C, Levi F et al. Trends in uterine cancer mortality in the Americas, 1955-1988. Gynecol Oncol 1993; 51: $335-344$.

62. IARC, Working Group on Evaluation of Cervical Screening Programmes. Screening for squamous cervical cancer: duration of low risk after negative results of cervical cytology and its implication for screening policies. BMJ 1986; 293: 659-664.

63. Peto J, Gilham C, Fletcher O, Matthews FE. The cervical cancer epidemic that screening has prevented in the UK. Lancet 2004; 364 : 249-256.

64. Robles SC, White F, Peruga A. Trends in cervical cancer mortality in the Americas. Bull Pan Am Health Organ 1996; 30: 290-301.

65. Arossi S, Sankaranarayanan R, Parkin DM. Incidence and mortality of cervical cancer in Latin America. Salud Publica Mex 2003; 45 (Suppl 3): S306-S314.

66. La Vecchia C. Epidemiology of ovarian cancer: A summary review. Eur J Cancer Prev 2001; 10: 125-129.

67. Bosetti C, Negri E, Trichopoulos D et al. Long-term effects of oral contraceptives on ovarian cancer risk. Int J Cancer 2002; 102: 262-265.

68. Alvarez YH, Guerra Yi ME, Garrote LF, Rodríguez RC. Incidence, mortality and survival from prostate cancer in Cuba, 1977-1999. Eur J Cancer Prev 2004; 13: 377-381.

69. Boyle P. Prostate cancer: creation and control of an epidemic. J Epidemiol Biostat 1996; 1: 65-67.

70. Tarone RE, Chu KC, Brawley OW. Implications of stage-specific survival rates in assessing recent declines in prostate cancer mortality rates. Epidemiology 2000; 11: 167-170.

71. Bolla M, Gonzalez D, Warde P et al. Improved survival in patients with locally advanced prostate cancer treated with radiotherapy and goserelin. N Engl J Med 1997; 337: 295-300.

72. Messing EM, Manola J, Sarosdy M et al. Immediate hormonal therapy compared with observation after radical prostatectomy and pelvic lymphadebectomy in men with node-positive prostate cancer. N Engl J Med 1999; 341: 1781-1788.
73. Kupelian PA, Buchsbaum JC, Elshaikh MA et al. Improvement in relapse-free survival throughout the PSA era in patients with localized prostate cancer treated with definitive radiotherapy: year of treatment an independent predictor of outcome. Int J Radiat Oncol Biol Phys 2003; 57: 629-634.

74. Hankey BF, Feuer EJ, Clegg LX et al. Cancer surveillance series: interpreting trends in prostate cancer-part I: evidence of the effects of screening in recent prostate cancer incidence, mortality, and survival rates. J Natl Cancer Inst 1999; 91: 1017-1024.

75. Levi F, La Vecchia C, Boyle P. The rise and fall of prostate cancer. Eur J Cancer Prev 2000; 9: 381-385.

76. Levi F, Lucchini F, Boyle P et al. Testicular cancer mortality in Eastern Europe. Int J Cancer 2003; 105: 574.

77. Boyle P. Testicular cancer: the challenge for cancer control. Lancet Oncol 2004; 5: 56-61.

78. Negri E, La Vecchia C. Epidemiology and prevention of bladder cancer. Eur J Cancer Prev 2001; 10: 714.

79. Iscovich J, Castelletto R, Esteve J et al. Tobacco smoking, occupational exposure and bladder cancer in Argentina. Int J Cancer 1987; 40: 734-740.

80. D’Avanzo B, Negri E, La Vecchia C et al. Cigarette smoking and bladder cancer. Eur J Cancer 1990; 26: 714-718.

81. La Vecchia C, Levi F, Lucchini $F$ et al. Trends in childhood cancer mortality as indicator of quality of medical care in the developed world. Cancer 1998; 83: 2223-2227.

82. Pui CH, Evans WE. Acute lymphoblastic leukemia. N Engl J Med 1998; 339: 605-615.

83. Levi F, Lucchini F, Negri $\mathrm{E}$ et al. Trends in mortality from leukemia in subsequent age groups. Leukemia 2000; 14: 1980-1985.

84. Linet MS, Cartwright RA. The Leukemias. In Schottenfeld D, JF Jr (eds): Cancer Epidemiology and Prevention, 2nd edition. New York: Oxford University Press 1996; 841-892.

85. Malvezzi M, Rodriguez T, Chatenoud L et al. Trends in cancer mortality in Mexico, 1970-1999. Ann Oncol 2004; 15: 1712-1718.

86. Garattini S, La Vecchia C. Perspectives in cancer chemotherapy. Eur J Cancer 2001; 37: S128-S147. 